\title{
CXCR4 and a cell-extrinsic mechanism control immature B lymphocyte egress from bone marrow
}

\author{
Thomas C. Beck, ${ }^{1}$ Ana Cordeiro Gomes, ${ }^{1}$ Jason G. Cyster, ${ }^{2,3}$ and João P. Pereira ${ }^{1}$ \\ 'Department of Immunobiology, Yale University School of Medicine, New Haven, CT 06520 \\ ${ }^{2}$ Howard Hughes Medical Institute and ${ }^{3}$ Department of Microbiology and Immunology, University of California, San Francisco, \\ San Francisco, CA 94143
}

Leukocyte residence in lymphoid organs is controlled by a balance between retention and egress-promoting chemoattractants sensed by pertussis toxin (PTX)-sensitive Gai proteincoupled receptors (GPCRs). Here, we use two-photon intravital microscopy to show that immature $B$ cell retention within bone marrow (BM) was strictly dependent on amoeboid motility mediated by CXCR4 and CXCL12 and by $\alpha 4 \beta 1$ integrin-mediated adhesion to VCAM-1. However, B lineage cell egress from BM is independent of PTX-sensitive GPCR signaling. B lineage cells expressing PTX rapidly exited BM even though their motility within $B M$ parenchyma was significantly reduced. Our experiments reveal that when immature $B$ cells are near BM sinusoids their motility is reduced, their morphology is predominantly rounded, and cells reverse transmigrate across sinusoidal endothelium in a largely nonamoeboid manner. Immature B cell egress from BM was dependent on a twofold CXCR4 downregulation that was antagonized by antigen-induced BCR signaling. This passive mode of cell egress from BM also contributes significantly to the export of other hematopoietic cells, including granulocytes, monocytes, and NK cells, and is reminiscent of erythrocyte egress.

\section{CORRESPONDENCE \\ João P. Pereira:}

joao.pereira@yale.edu

Abbreviations used: GPCR, Gai protein-coupled receptor; HEL, hen egg lysozyme; IVM, intravital microscopy; $\mathrm{PB}$, peripheral blood; PTX, pertussis toxin.
Leukocyte egress from lymphoid organs is a multistep process characterized by active cell migration mediated by pertussis toxin (PTX)sensitive Gai protein-coupled receptors (GPCRs) toward exit sites, followed by reverse transmigration across endothelial barriers. Lymphocyte egress from thymus and lymph nodes is highly dependent on the chemoattractant lipid sphingosine 1 phosphate $(\mathrm{S} 1 \mathrm{P})$, which is abundant in circulatory fluids (blood and lymph) while limited in the lymphoid organ interstitium. The $\mathrm{S} 1 \mathrm{P}$ gradient is sensed by lymphocytes through intrinsic expression of the PTX-sensitive GPCR $\mathrm{S} 1 \mathrm{P}$ receptor $1\left(\mathrm{~S} 1 \mathrm{PR}_{1}\right) \cdot \mathrm{S} 1 \mathrm{PR}_{1}$ deficiency causes $\sim 50-1,000-$ fold reduction in $\mathrm{T}$ and $\mathrm{B}$ lymphocyte numbers in blood and lymph concomitant with their significant accumulation in lymphoid organs (Cyster and Schwab, 2012).S1PR mRNA expression is driven by the transcription factor Krüppel-like factor-2 (KLF2) in developing thymocytes and in naive $\mathrm{T}$ lymphocytes (Carlson et al., 2006; Bai et al., 2007). Of note, KLF2 transcription is dependent on the FOXO1 transcription factor (Fabre et al., 2008; Gubbels Bupp et al., 2009; Kerdiles et al., 2009), and in
$\mathrm{T}$ cells FOXO1 is sequestered in the cytoplasm and rendered transcriptionally inactive via phosphorylation mediated by the serine/threonine kinase AKT (Fabre et al., 2005). This molecular circuitry seems to ensure that only the negatively selected thymocytes undergoing low TCR signaling achieve sufficient $\mathrm{S}_{\mathrm{PR}}$ expression for exiting the thymus. In contrast, $\mathrm{S} 1 \mathrm{P}$ and its receptors play a modest role in mediating cell egress from $\mathrm{BM}$, as genetic or pharmacologically induced S1P receptor deficiency only accounts for approximately two- to threefold reduction in immature B lymphocyte, NK cell, and eosinophil export from BM (Walzer et al., 2007; Jenne et al., 2009; Allende et al., 2010; Pereira et al., 2010; Sugita et al., 2010). S1PR 1 mRNA expression is largely independent of KLF2 expressed in developing and mature B lymphocytes (Hart et al., 2011), thus making it unlikely that the $\mathrm{S} 1 \mathrm{P} / \mathrm{S} 1 \mathrm{PR}_{1}$ egress pathway is under the

Q 2014 Beck et al. This article is distributed under the terms of an AttributionNoncommercial-Share Alike-No Mirror Sites license for the first six months after the publication date (see http://www.rupress.org/terms). After six months it is available under a Creative Commons License (Attribution-NoncommercialShare Alike 3.0 Unported license, as described at http://creativecommons.org/ licenses/by-nc-sa/3.0/) 
control of BCR signaling induced in immature B lymphocytes during negative selection in BM. The mechanism or mechanisms used by immature B lymphocytes for exiting BM thus remain essentially unknown.

Whereas T cells comprise the vast majority of cells exported from the thymus, all other hematopoietic cells, and several nonhematopoietic cells, are produced in and exported from the BM. Neutrophils and monocytes use the GPCRs CXCR2 and CCR2 for BM egress, respectively; however, deficiency in either receptor reduced BM export by less than sevenfold (Serbina and Pamer, 2006; Eash et al., 2010; Shi et al., 2011). Why are lymphocytes highly sensitive to $\mathrm{S}_{\mathrm{PR}} \mathrm{P}_{1}$-dependent mechanisms for exiting thymus and lymph nodes, whereas other hematopoietic cells, including lymphocytes, are marginally dependent on single GPCR-dependent mechanisms for egress from BM? One possibility is that redundancy with multiple GPCRs controls egress of different cell lineages from BM. Alternatively, the fact that millions of red blood cells are produced and exported daily from BM (Lichtman and Santillo, 1986), and that these cells lack mechanisms for interstitial amoeboid cell migration, raises the possibility that alternative mechanisms control hematopoietic cell egress from BM.

CXCR4 is a PTX-sensitive GPCR that signals the BM homing and retention of multiple hematopoietic cell lineages, including hematopoietic stem and progenitor cells, monocytes, neutrophils, NK cells, B cells, and plasma cells (Ma et al., 1999; Hargreaves et al., 2001; Lapidot and Kollet, 2002; Liles et al., 2003; Broxmeyer et al., 2005; Bernardini et al., 2008; Pereira et al., 2009; Wang et al., 2009b; Eash et al., 2010). CXCL12, the CXCR4 ligand, is a potent chemoattractant to various hematopoietic cells and is abundantly expressed by stromal cells, osteoblasts, and endothelial and perivascular cells in BM (Sugiyama et al., 2006; Ding and Morrison, 2013). CXCR4/CXCL12 counteracts the activity of egress-promoting cues in immature B cells, neutrophils, NK cells, and monocytes (Bernardini et al., 2008; Wang et al., 2009b; Allende et al., 2010; Eash et al., 2010), though how CXCR 4 signaling antagonizes cell egress remains unknown.

In this study, we demonstrate that CXCR 4 signaling controls B lineage cell motility within BM parenchyma. Furthermore, developing B cell migration is strictly dependent on $\alpha 4 \beta 1$ integrin-mediated adhesion toVCAM-1.The BM parenchyma is extensively perfused by blood flow, which presumably imposes significant shear stress on BM-resident cells. Deficiency in CXCR 4-mediated B lineage cell motility in BM parenchyma resulted in their acute mobilization from BM into periphery. Likewise, B lineage cells expressing PTX are predominantly nonmotile in BM parenchyma and are efficiently mobilized into the periphery. Our experiments revealed that the critical mechanism regulating $\mathrm{B}$ lineage cell egress from $\mathrm{BM}$ is a twofold down-regulation of CXCR 4 in immature B cells, which depolarizes their amoeboid shape, reduces cell movement in perisinusoidal niches, and facilitates export into BM sinusoids and peripheral organs. Notably, antigen engagement by immature $\mathrm{B}$ cells prevents CXCR 4 down-regulation, increases B lineage cell motility in BM parenchyma, and blocks egress from BM.

\section{RESULTS}

\section{CXCR4 controls B lineage cell movement within BM}

We examined how CXCR 4 inhibits BM egress by visualizing the dynamic behavior of developing B lymphocytes within calvarial BM of Rag $1^{\mathrm{GFP} /+}$ mice by two-photon intravital microscopy (IVM) before and after disruption of CXCR 4 signaling. Mice were injected i.v. with fluorescently labeled dextrans to allow distinguishing BM parenchyma from sinusoids. Approximately $99.8 \%$ of $\mathrm{GFP}^{+}$cells in $\mathrm{BM}$ are $\mathrm{B}$ lineage cells (99.5\% B220 ${ }^{+}$cells and $0.3 \% \mathrm{~B} 220^{\text {lo }} \mathrm{CD}^{+} 3^{+}$early B lineage progenitors), $\sim 0.1 \%$ are $\mathrm{CD} 3 \mathrm{e}^{+} \mathrm{T}$ cells (presumably recent thymic emigrants), and $\mathrm{CD} 3 \mathrm{e}^{-} \mathrm{NK} 1.1^{+}$cells were all found to be $\mathrm{GFP}^{-}$(not depicted). $\mathrm{GFP}^{+} \mathrm{B}$ lineage cells displaced throughout the 30-min imaging period (Fig. 1, A and B) at a median velocity of $2.4 \mu \mathrm{m} / \mathrm{min}$ (Fig. $1 \mathrm{C}$ ), as expected (Pereira et al., 2009). However, cells rapidly stopped their migration 1-2 min after treatment with $80 \mu \mathrm{g}$ of the CXCR 4 antagonists AMD3100 or TN14003 (Tamamura et al., 2001) i.v. or $1 \mathrm{~h}$ after treatment with CXCL12 blocking antibody (Fig. 1, $\mathrm{A}$ and $\mathrm{B}$; and Video 1). The sudden arrest led to a significant reduction in the median velocity (Fig. 1 C) and mean displacement (Fig. 1 D), which were reflected in a 6-10-fold reduction of the mean motility coefficient (Fig. 1 B). CXCR 4 signaling blockade also changed $\mathrm{B}$ cell morphology from an amoeboid/elongated form to a significantly rounded shape (Fig. 1, $\mathrm{E}$ and F; and Video 1). The effects of AMD3100 were reversible after $2-3 \mathrm{~h}$, with most cells regaining an amoeboid shape and motility (not depicted), which is in agreement with its rapid decay rate in vivo (Hendrix et al., 2000). These data suggested an intrinsic requirement for CXCR 4 for B cell migration in vivo. Indeed, B cells conditionally deficient in CXCR 4 moved within $\mathrm{BM}$ with a significantly reduced median velocity (Fig. $1 \mathrm{H}$ and Video 2) and were more rounded than WT B cells (Fig. 1 I). However, most cells were not entirely stopped (Video 2), and their mean motility coefficient was only reduced by $\sim 40 \%$ (Fig. 1 G). Treatment with AMD3100 (80 $\mu \mathrm{g}$ i.v.; Video 3) further reduced the velocity and mean motility coefficient of CXCR4-deficient B cells and increased their roundness (Fig. 1, G-I). The similar activities of the three CXCR 4 signaling inhibitors reduced the probability that B cell motility defects were caused by off-target effects. Also, in vitro $\mathrm{B}$ cell migration toward the chemokine CXCL13 was unaffected by treatment with AMD3100 (not depicted). Genetic and pharmacological CXCR 4 deficiency also led to the significant mobilization of developing B cell subsets from BM into blood (Fig. $1 \mathrm{~J}$ ), as expected (Nie et al., 2004; Pereira et al., 2009). As CXCR 4 is critically required for B lineage cell retention in $\mathrm{BM}$, it is possible that the few $\mathrm{GFP}^{+} \mathrm{B}$ lineage cells observed in calvaria BM of CXCR 4 conditionally deficient mice had residual CXCR 4 signaling that was sufficient for promoting BM retention and migration. Indeed, some CXCR 4 conditionally deficient B lineage cells exhibited low CXCR4 surface expression (not depicted). Nevertheless, these data do not exclude the possibility that lymphocyte-extrinsic CXCR 4 contributes to B lineage cell motility in BM. 

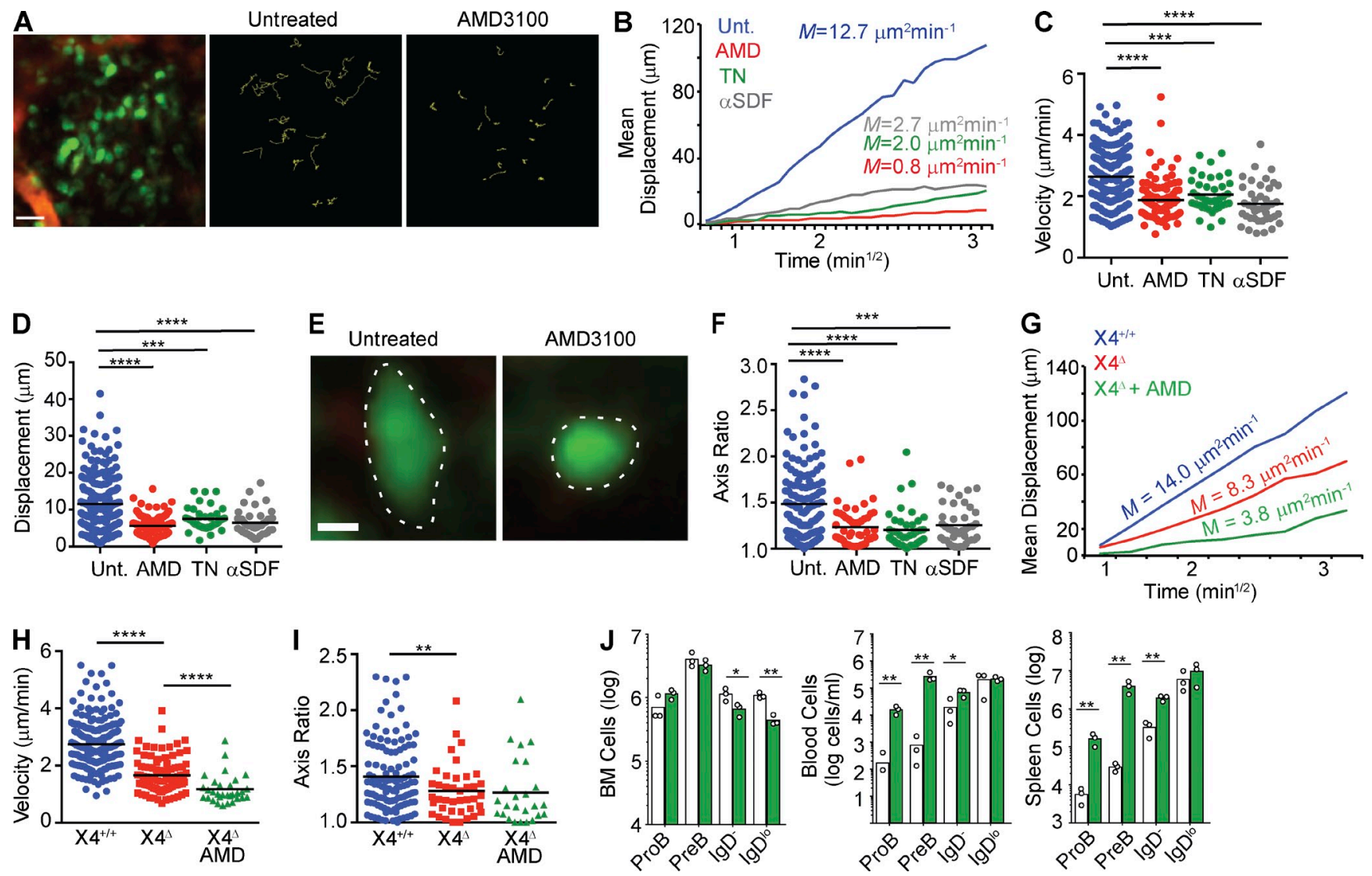

Figure 1. CXCR4 antagonism inhibits B lineage cell migration in BM. (A-F) Rag 19FP/+ mice were injected i.v. with AMD3100, TN14003, or antiCXCL12 antibody. Blood vessels were labeled with 2,000-kD dextran-rhodamine injected i.v. Cell movement was tracked by IVM of calvaria immediately before and after treatment. ( $\mathrm{A}$, left) Distribution of GFP+ B cells (green) in BM. (middle and right) Movement of GFP+ B cells tracked for 30 min before and after AMD3100 treatment, respectively. Colored lines represent cell trajectories. Data are representative of three individual experiments. (B) Mean motility coefficient of B lineage cells before (blue) and after (red) treatment with CXCR4 antagonists. Cell displacement from starting coordinates is plotted against the square root of time. Lines depict the average mean motility coefficient calculated from three individual experiments. (C) Median velocity ( $\mu$ m/min). (D) Displacement $(\mu \mathrm{m})$. (E) Morphology of GFP+ B lineage cells before (left) and after (right) AMD3100 treatment. Dotted lines depict the cells' borders. Bars: (A) $20 \mu \mathrm{m}$; (E) $30 \mu \mathrm{m}$. (F) Measurement of cell axis ratio of GFP+ B lineage cells before (blue) and after (red) treatment with CXCR4 inhibitors. (G-I) WT (Mb1 ${ }^{\mathrm{Cre} /+}$ ) and CXCR4 KO (Mb $1^{\mathrm{Cre} /+} \mathrm{CXCr} 4^{\mathrm{Fl} /-}$ ) were treated as in A-F. (G) Mean motility coefficient of WT (blue) and CXCR4 KO (red) B lineage cells before (red) and after (green) treatment with AMD3100. Colored lines depict average mean motility coefficient calculated from three independent datasets. (H) Median cell velocity of WT (blue) and CXCR4 KO (red) B lineage cells before (red) and after (green) treatment with AMD3100. (I) Cell axis ratio of GFP+

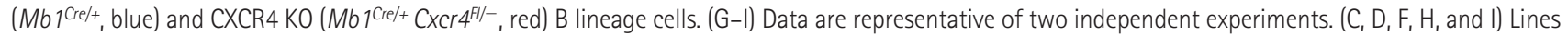
indicate mean. (J) Enumeration of B lineage cells in BM, blood, and spleen of $\mathrm{Mb}_{1} \mathrm{Cre}^{++} \mathrm{CXCr} 4^{+/+}$(open bars) and $\mathrm{Mb}_{1} \mathrm{Cre}_{++} \mathrm{CXCr} 4^{\mathrm{Fl} /-}$ (green bars) mice. Bars indicate mean, and circles indicate individual mice. Data are representative of three independent experiments. ${ }^{*}, \mathrm{P}<0.05 ;{ }^{* *}, \mathrm{P}<0.005 ;{ }^{* * *}, \mathrm{P}<0.0005$; ${ }^{* * * *}, \mathrm{P}<0.00005$ by unpaired Student's $t$ test.

\section{Integrin-dependent B lineage cell migration in BM}

Leukocyte migration is independent of integrin-mediated adhesion within lymphoid organ interstitium (Woolf et al., 2007; Lämmermann et al., 2008). In contrast, leukocytes require integrins for migration on two-dimensional surfaces (haptokinetic migration), such as migration along luminal endothelium toward the site of diapedesis (Alon and Feigelson, 2009). The cell shape changes that occurred immediately after treatment with CXCR4 inhibitors suggested that CXCR4 was involved in promoting $\mathrm{B}$ cell adhesion to the BM extracellular matrix and raised the possibility that B lymphocyte migration within BM interstitium was haptokinetic (i.e., integrin dependent). Consistent with this possibility, CXCR 4 signaling increases $\alpha 4 \beta 1$ integrin affinity for its ligand VCAM-1, and both contribute to B lineage cell retention in BM (Koni et al., 2001; Leuker et al., 2001; Glodek et al., 2003; Pereira et al., 2009). To test this hypothesis, we analyzed B cell motility within BM parenchyma of Rag $1^{G F P /+}$ mice by IVM before and after i.v. administration of $200 \mu \mathrm{g}$ anti- $\alpha 4$ (clone PS/2) or anti-VCAM-1 (clone M/K-2) blocking antibodies. B cell migration was largely blocked after treatment with anti- $\alpha 4$ or anti-VCAM-1 antibodies (Fig. 2 A and Video 4). There was a sixfold reduction of the mean motility coefficient (Fig. 2 B), reduced cell velocity (Fig. 2 C), and increased cell roundness (Fig. 2 D). The requirement for $\alpha 4 \beta 1$ integrinmediated haptokinesis was intrinsic to B lineage cells as similar 
A
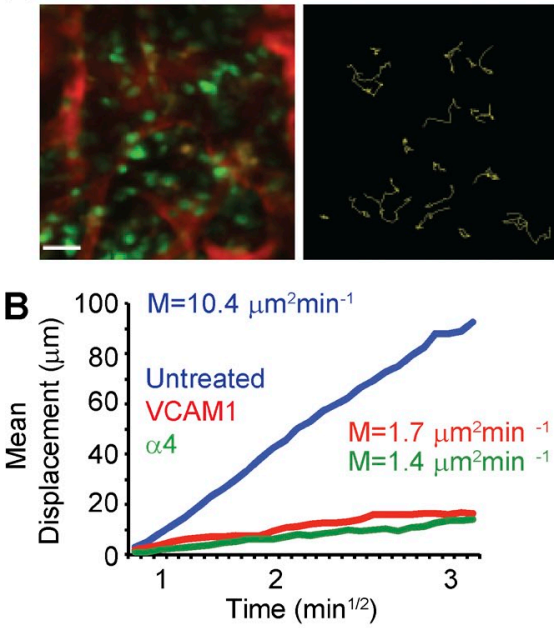

E

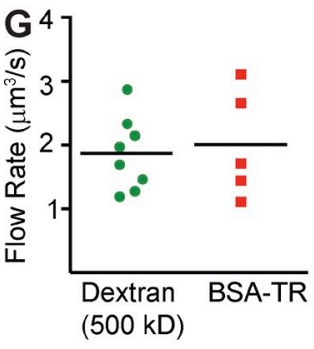

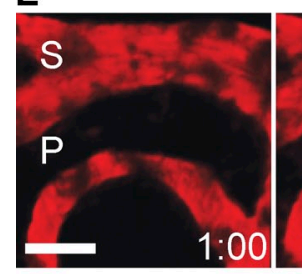

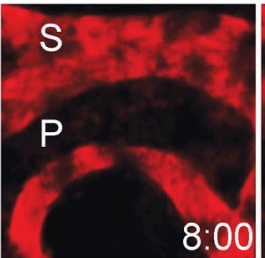

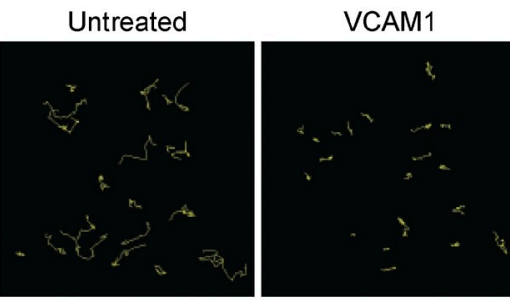

C
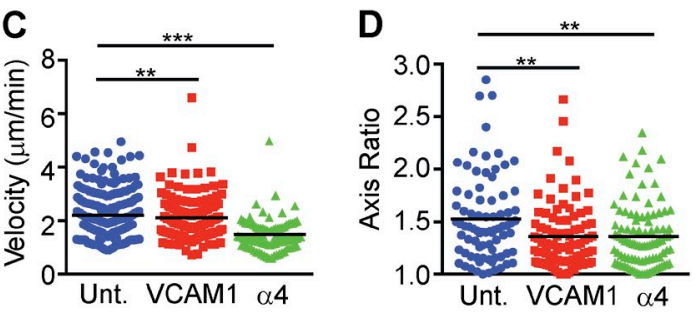
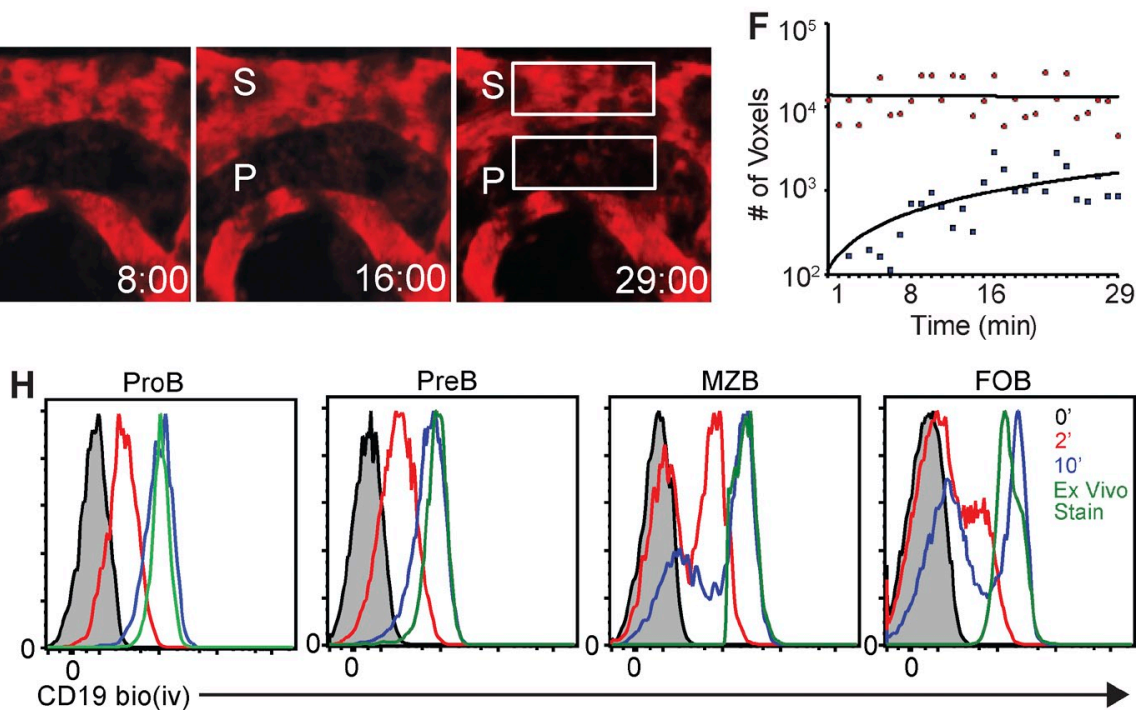

Figure 2. Developing B cell motility in BM parenchyma is strictly dependent on $\alpha \mathbf{4 \beta 1}$ integrin-mediated adhesion to VCAM-1. (A-D) Rag 1 $^{G F P /+}$ were injected (i.v.) with integrin $\alpha 4$ or VCAM-1 blocking antibodies, and calvarial BM was imaged before and immediately after treatment. Blood vessels were labeled with 2,000-kD dextran-rhodamine injected i.v. (A, left) Distribution of GFP+ B cells (green) in BM. (middle and right) Movement of GFP+ $B$ cells tracked for 30 min before and after treatment with anti-VCAM-1 antibody. Colored lines represent cell trajectories. (B) Mean motility coefficient of $B$ lineage cells before (blue line) and after VCAM-1 (red) and $\alpha 4$ blockade (green). Lines depict the average mean motility coefficient calculated from three independent experiments. (C) Median velocity ( $\mu \mathrm{m} / \mathrm{min}$ ). (D) Cell axis ratios before (blue) and after treatment with VCAM-1 (red) and $\alpha 4$ (green) blocking antibodies. The data are representative of three independent experiments. ( $C$ and D) Lines indicate mean. (E) Mice were injected with $50 \mu \mathrm{g}$ of $500-\mathrm{kD}$ FITC-conjugated dextran (i.v.), and calvaria BM was imaged before and after treatment. BM vasculature (S) and parenchyma (P) are indicated. White boxes delineate regions of interest used for measurements of dextran perfusion. Time is shown in each panel (mm:ss). (A and E) Bars, $20 \mu m$. (F) FITC-conjugated dextran perfusion of BM parenchyma and vasculature (red fluorescent voxels; $y$ axis) over 30 min (time; $x$ axis). Data are representative of $>10$ independent experiments. (G) Interstitial fluid flow rate $\left(\mu \mathrm{m}^{3} / \mathrm{s}\right.$ ) determined after injection (i.v.) of FITC-dextran ( $500 \mathrm{kD}$; green) or BSA-Texas red (red). Lines indicate the mean; symbols represent regions of interest obtained from three mice (FITC-dextran) or from two mice (BSA-Texas red). (H) In vivo staining of pro-B and pre-B cells in BM and of marginal zone (MZB) and follicular (FOB) B cell subsets in spleen with biotin-anti-CD19 antibody administered i.v. for 2 (red) or 10 (blue) min. Saturation with anti-CD19 antibody was determined by ex vivo staining with excess antibody (green). Data are representative of three independent experiments. ${ }^{* *}, \mathrm{P}<0.005 ;{ }^{* *}, \mathrm{P}<0.0005$ by unpaired Student's $t$ test.

observations were made in Itgb1-deficient B lymphocytes (Video 5). Treatment with anti- $\alpha 4$ blocking antibody did not change the dynamic behavior of Itgb1-deficient B cells (not depicted). Interestingly, loosely adherent and rounded cells were seen occasionally moving short distances for a brief period (Video 6). The number of developing B cells was significantly reduced in BM, which corresponded to a significant increase in peripheral blood (PB; not depicted), as expected (Pereira et al., 2009). Electron microscopy analyzes of the BM sinusoidal endothelium demonstrated that it is highly fenestrated (Tavassoli and Yoffey, 1983). Consistent with these observations, the BM vasculature was permeable to large-molecular-mass, FITC-coupled 
dextrans $(\sim 500 \mathrm{kD})$ present in circulatory fluids (Fig. 2, E and F; and Video 7), and blood plasma perfusion reached an interstitial fluid flow rate of $\sim 2 \mu \mathrm{m}^{3}$ /s (Fig. $2 \mathrm{G}$ ). The extensive perfusion of the BM parenchyma within minutes of injection of intravascular dyes is consistent with BM-resident cells being continuously exposed to shear stress generated by fluid flow. Indeed, considering that the femur volume is $<100 \mu \mathrm{m}^{3}$ (our unpublished estimates), we hypothesized that circulatory molecules access the entire femur BM parenchyma in $<2$ min. To test for this possibility, we injected $5 \mu \mathrm{g}$ biotin-conjugated anti-CD19 antibody i.v., allowed it to equilibrate for 2 or $10 \mathrm{~min}$, and measured the extent of binding to pro-B and pre-B cells in BM. For comparison we examined labeling of splenic follicular and marginal zone B cells of the same mouse. Our data show that the large majority of pro-B and pre-B cells are readily labeled with anti-CD19 within $2 \mathrm{~min}$, and by $10 \mathrm{~min}$ $100 \%$ of each B cell subset is saturated with circulatory antibody (Fig. $2 \mathrm{H}$ ). In contrast, a significant fraction of mature follicular B cells in the spleen is poorly stained even after $10 \mathrm{~min}$ of exposure to biotin anti-CD19 antibody in circulation. As expected, the marginal zone B cell subset was readily stained with anti-CD19 antibodies after $2 \mathrm{~min}$ (Cinamon et al., 2008), but saturation was only achieved after $10 \mathrm{~min}$ (Fig. $2 \mathrm{H}$ ). These data demonstrate that circulatory molecules rapidly perfuse BM parenchyma. Whether lymphocytes access BM exit sites by forces induced upon cells, such as interstitial fluid flow, or exclusively by active migration guided by chemoattractants sensed by GPCRs intrinsically expressed on lymphocytes was not clear.

\section{$B$ lineage cell egress from BM is independent of GPCR-guided amoeboid motility}

The findings that CXCR 4 blockade significantly reduced B lineage cell motility in parenchyma while accelerating egress into sinusoids and $\mathrm{PB}$ raised an interesting and unprecedented possibility: that BM egress could be achieved in the absence of amoeboid migration toward BM exit sites. To test this hypothesis, we conditionally induced PTX expression in B lineage cells by crossing $M b 1^{\mathrm{Cre} /+}$ mice with mice encoding the ADP-ribosyl transferase S1 subunit of PTX within the Rosa26 locus, preceded by a premature transcriptional stop codon flanked by loxP sites (for simplicity referred as Rosa $26^{\text {PTX/+ }}$ mice; Regard et al., 2007). Using this strategy, $>99 \%$ of B lineage cells conditionally express genes under Rosa 26 promoters from the pro-B cell stage and throughout subsequent stages of development (not depicted). The number of pro-B and pre-B cells was slightly but significantly reduced in BM, which corresponded to a small, but highly significant numerical increase in blood circulation (Fig. 3, A and B). However, IgM ${ }^{+}$ immature B cell subsets were reduced by two- to threefold in $\mathrm{BM}$ and significantly increased in blood, indicating increased BM egress. We did not find evidence of bystander effects, such as PTX leakiness into neighboring cells in BM mixed chimeras (not depicted). Furthermore, similar findings were obtained with B lineage cells deficient in Gnai2 and Gnai3 (Hwang et al., 2013). PTX-expressing B lineage cells were also poorly retained within BM sinusoids (not depicted), consistent with a role for Gai-coupled $\mathrm{CB} 2$ and S1PR3 in this process (Pereira et al., 2009; Donovan et al., 2010). Mature B lymphocytes were also reduced in BM (Fig. 3 A) because CXCR4 coupling to Gai proteins is PTX sensitive, and mature B cells require CXCR4 for homing back to BM (Nie et al., 2004; Pereira et al., 2009).

To investigate whether B lineage cell motility within BM was dependent on PTX-sensitive GPCRs, we visualized the behavior of PTX-expressing B cells marked with a Rag $1^{\mathrm{GFP} /+}$ allele in calvaria BM by IVM. We found that PTX-expressing B cells were predominantly nonmotile (Fig. 3, C and D; and Video 8) and exhibited rounded morphology (Fig. 3 E). Occasionally, we found BM pockets with some PTX-expressing $\mathrm{B}$ cells moving in an amoeboid manner with similar kinetics as WT cells (Video 9), but their migration was sensitive to CXCL12 blocking antibody treatment (Fig. 3 F). These findings suggest that CXCR 4 can couple to PTX-insensitive G proteins in B cells and promote interstitial migration in vivo. In agreement with these observations, AMD3100 blocked the chemotaxis of WT and PTX-expressing developing B cell subsets toward a CXCL12 gradient in vitro, whereas CXCR4deficient $\mathrm{B}$ cells were unable to migrate in similar conditions (not depicted). Finally, we asked whether other hematopoietic cells could leave BM independently of PTX-sensitive GPCRs. To address this question, we treated mice with $1 \mu \mathrm{g}$ PTX i.v. for $24 \mathrm{~h}$ and quantified hematopoietic cell egress from BM into PB by flow cytometry. NK cells, neutrophils, and inflammatory monocytes, like B lineage cells, were efficiently mobilized from BM into PB by PTX treatment (Fig. 3 G), even though PTX-sensitive GPCRs can contribute to their export from BM (Serbina and Pamer, 2006; Walzer et al., 2007; Jenne et al., 2009; Allende et al., 2010; Eash et al., 2010; Pereira et al., 2010). Similar results were obtained by cre recombinasemediated PTX expression in granulocytes and monocytes and in NK cells, driven by $L y z 2$ (Clausen et al., 1999) or by $I l 7 r$ (Schlenner et al., 2010), respectively (not depicted).

The increased rate of BM B cell egress seen in CXCR4deficient mice, or in PTX-expressing B cells, suggested that defective motility within parenchyma enforced B lineage cells to position near BM sinusoids. To address this possibility, we measured the distance between WT, CXCR4-deficient, and PTX-expressing B lineage cells and BM sinusoids and found that both CXCR4-deficient and PTX-expressing cells were significantly accumulated in proximity to sinusoids (perisinusoidal space was defined as the area that is $<10 \mu \mathrm{m}$ distal from sinusoids; Fig. 4, A and B). As CXCR 4 controls the movement of B lineage cells in parenchyma and the lack of CXCR 4 signaling positions cells around sinusoids (Fig. 4, A and B) and within sinusoids (Pereira et al., 2009), we hypothesized that B lineage cells moving within perisinusoidal niches had reduced motility. Thus, we analyzed the dynamic behavior of B lineage cells that moved within 10- $\mu \mathrm{m}$ distance to sinusoids and compared them with cells moving in parenchymal areas of the same imaging volume. Even though there was a trend toward reduced median velocity that did not reach statistical significance 

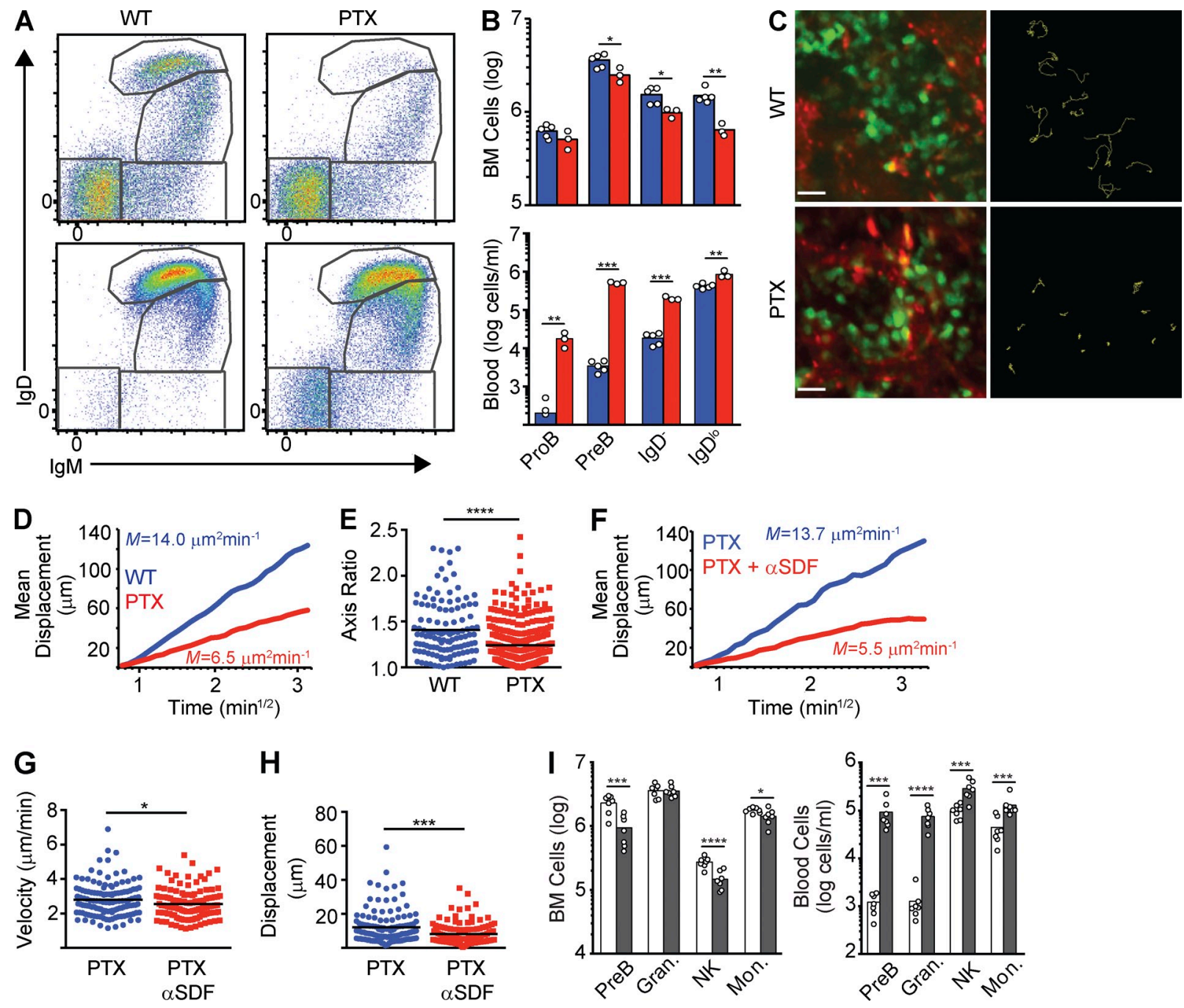

Figure 3. B cells egress $B M$ independently of GPCR-mediated migration. (A) IgM and $\lg D$ expression in live gated (DAPI-) $B 220^{+}$cells in $B M$ (top) and PB (bottom) of $\mathrm{Mb}_{1}{ }^{\mathrm{Cre} /+}$ (WT, left) and Mb1 ${ }^{\mathrm{Cre} /+}$ Rosa26 $6^{\text {PTX/+ }}$ mice (PTX, right). (B) Quantification of developing B cell subsets in BM (top) and $\mathrm{PB}$ (bottom) of $\mathrm{Mb} 7^{\mathrm{Cre} /+}$ mice (blue bars) and $\mathrm{Mb}_{1}{ }^{\mathrm{Cre} /+}$ Rosa26 $6^{\mathrm{PTX} /+}$ mice (red bars). Bars indicate mean, and circles depict individual mice analyzed. Data are representative of more than three independent experiments. (C) IVM of PTX-expressing B lineage cells in calvaria BM. Blood vessels were visual-

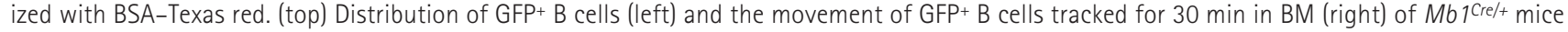
(WT). (bottom) Distribution of GFP+ B cells (left) and the movement of GFP+ B cells tracked for 30 min in BM (right) of Mb1 Cre/+ Rosa26 PTX/+ mice (PTX). Colored lines represent cell trajectories. The data are representative of at least three independent experiments. Bars, $20 \mu \mathrm{m}$. (D) Mean motility coefficient of WT and PTX-expressing B lineage cells. Lines depict the average mean motility coefficient calculated from three independent mice. (E) Cell axis ratios of WT and PTX-expressing cells. (F-H) Analysis of the mean motility coefficient (F), median velocity $(\mu \mathrm{m} / \mathrm{min} ; \mathrm{G})$, and displacement ( $\mu$ m; $H$ ) of PTX-expressing B lineage cells before (blue) and after treatment with $250 \mu \mathrm{g}$ anti-CXCL12 antibody ( $\alpha$ SDF, red). M indicates mean motility coefficient in $\mu \mathrm{m}^{2} / \mathrm{min}$. Lines depict the average mean motility coefficient calculated from datasets obtained by IVM of three different mice. $\left(E_{1}, G\right.$ and $\left.H\right)$ Lines indicate mean. (I) Numbers of pre-B cells, NK cells, granulocytes (Gran.) and inflammatory monocytes (Mon.) in BM and PB of WT mice treated with saline (open bars) or with $1 \mu \mathrm{g}$ PTX for $24 \mathrm{~h}$ (gray bars). Data are representative of more than three independent experiments. ${ }^{*}, \mathrm{P}<0.05 ;{ }^{* *}, \mathrm{P}<0.005$, ${ }^{* * *}, \mathrm{P}<0.0005 ;{ }^{* * *}, \mathrm{P}<0.00005$ by unpaired Student's $t$ test.

(Fig. 4 C), their motility coefficient was reduced by 35\% (Fig.4 D), and cells within perisinusoidal niches were significantly less amoeboid (Fig. 4 E). B cells were only rarely observed migrating across sinusoidal endothelium before or after CXCR4 blockade, or in B cells genetically deficient in CXCR4 or in G $\alpha$ i protein-dependent receptors. This was not surprising because the numerical increase of Gai protein- or CXCR4deficient B cell subsets in blood is $\sim 10-100$-fold lower than the total number of B lineage cells remaining in BM (Fig. 3, $\mathrm{A}$ and $\mathrm{B}$; and not depicted, respectively). Furthermore, the relatively small number of B lineage cells visualized and the limited volume of imaging fields make it difficult to capture B cells transmigrating across sinusoidal endothelial barriers. However, in $\sim 18 \mathrm{~h}$ of IVM of untreated WT $\left(\operatorname{Rag} 1^{\mathrm{GFP} /+}\right)$ mice and in $3 \mathrm{~h}$ of IVM of PTX-expressing B cells, we were able to observe reverse transmigration of 11 and $2 \mathrm{~B}$ lineage cells, 
A
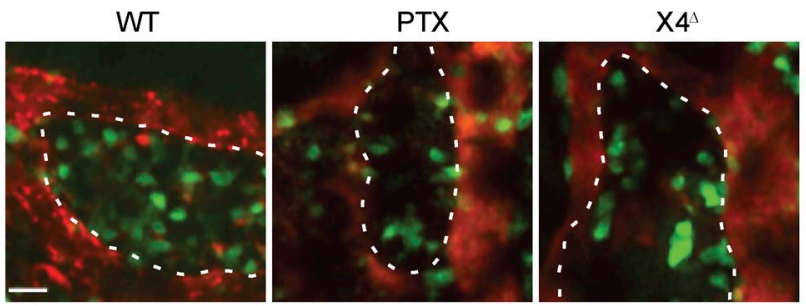

C

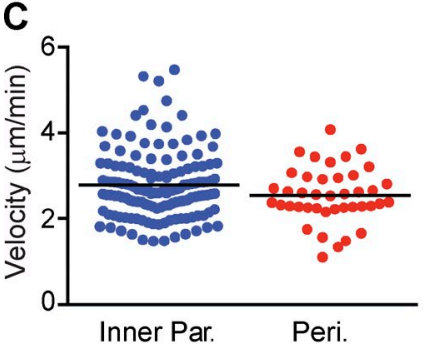

D

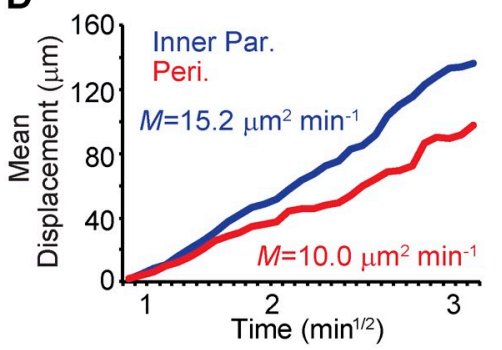

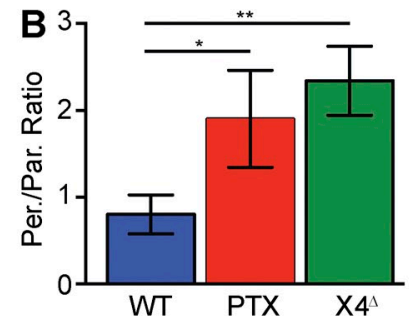

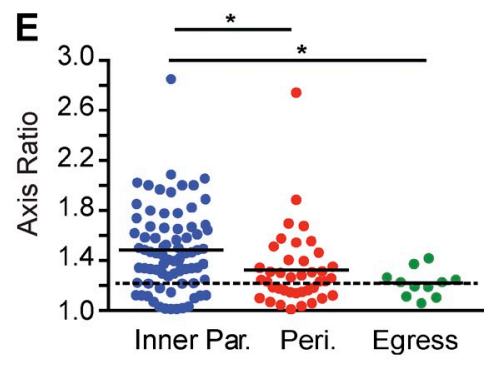

\section{$\mathbf{F}$}
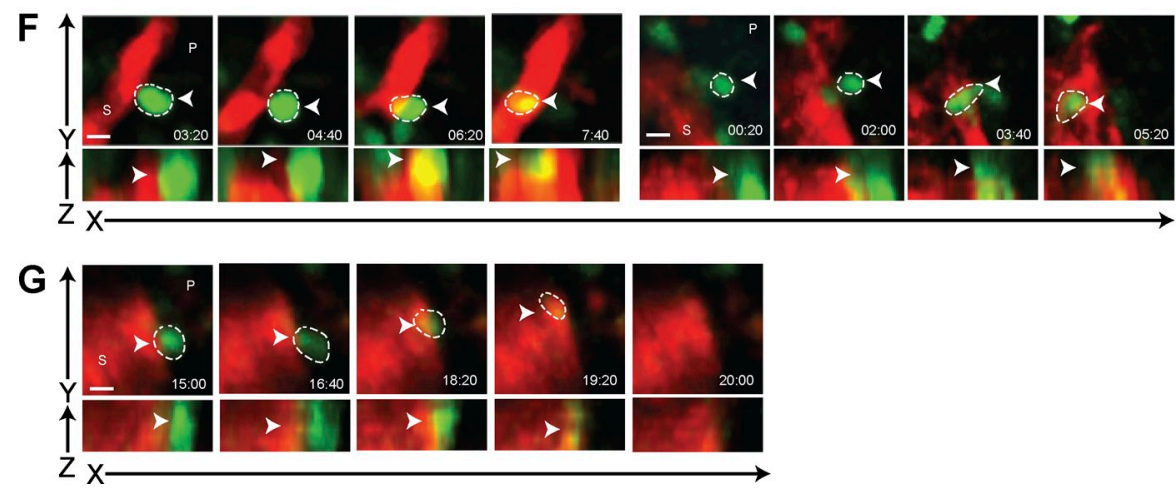

Figure 4. Morphology and motility of developing B cells during BM egress. (A) Distribution of $B$ lineage (Rag $\left.1^{\mathrm{GFP} /+}\right)$ cells in $\mathrm{BM}$ of $\mathrm{Mb}^{\mathrm{Cre} /+}$

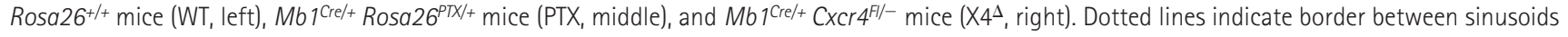
and parenchyma. (B) Ratio of B lineage cells proximal $(<10 \mu \mathrm{m})$ and distal $(>10 \mu \mathrm{m})$ to BM sinusoids. Data depicted were from $>90 \mathrm{~B}$ lineage cells analyzed in three WT, PTX, and X $4^{\Delta}$ mice. Bars indicate mean $( \pm$ SEM). (C-E) Cell motility parameters of developing $B$ cells in parenchyma and in perisinusoidal space. (C) Median velocity ( $\mu \mathrm{m} / \mathrm{min}$ ). (D) Mean motility coefficient of Rag $1^{\mathrm{GFP} /+} \mathrm{B}$ lineage cells in inner parenchyma (Inner Par. blue) and in perisinusoidal areas (Per. red). Mean cell displacement from starting coordinates is plotted against the square root of time. Lines depict the average mean motility coef-

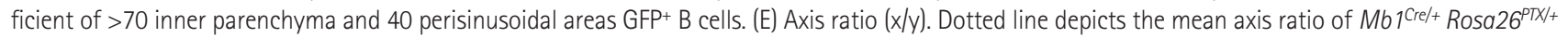
B cells in BM parenchyma (1.2). (C and E) Lines indicate means. ( $F$ and G) Two WT GFP+ B cells (F) and one PTX-expressing GFP+ B cell (G) exiting from BM parenchyma (P) into sinusoids (S). Arrowheads point to cell egress. Time is shown in mm:ss. WT and PTX-expressing cell egress examples were captured from more than 10 and 4 independent experiments, respectively. Bars: (A) $19 \mu \mathrm{m}$; (F and G) $5 \mu \mathrm{m} .{ }^{*}, \mathrm{P}<0.05 ;{ }^{* *}, \mathrm{P}<0.005$ by unpaired Student's $t$ test. Unpaired Student's $t$ test with Welch's correction was used in $\mathrm{E}$.

respectively. In all examples observed, B lineage cells that exited BM parenchyma into sinusoids did not approach BM exit sites in an amoeboid manner, were poorly motile, and resided adjacent to sinusoids (Video 10). Consistent with our previous findings, we did not observe morphological differences between WT and PTX-expressing B cells in the process of exiting into sinusoids (Fig. 4, F and G; and Video 10), even though PTX-expressing B cells were rapidly displaced into circulation after entry into sinusoids, whereas WT B lineage cells were retained in this compartment, as expected (Pereira et al., 2009; Donovan et al., 2010). Interestingly, reverse transmigration occurred exclusively in areas where the sinusoidal endothelial barrier exhibited intense vascular leakage (Video 10). In some cases, WT and PTX-expressing cells deformed during reverse transmigration, which strongly suggests that reverse transmigration across BM sinusoidal endothelium is an active process that is independent of GPCR signaling.

\section{Gradual reduction in CXCR4 expression reduces motility and enforces immature $B$ cell egress from BM}

Previous studies have shown that CXCR 4 expression is highest at the pro-B cell stage and decreases gradually during murine and human B cell development (Honczarenko et al., 1999; Pereira et al., 2009). The finding that perisinusoidal B lineage cells exhibited reduced motility and increased roundness suggested that CXCR 4 signaling was reduced in egress-competent cells. To investigate this possibility, we compared CXCR4 expression on immature B lymphocyte subsets before and after 

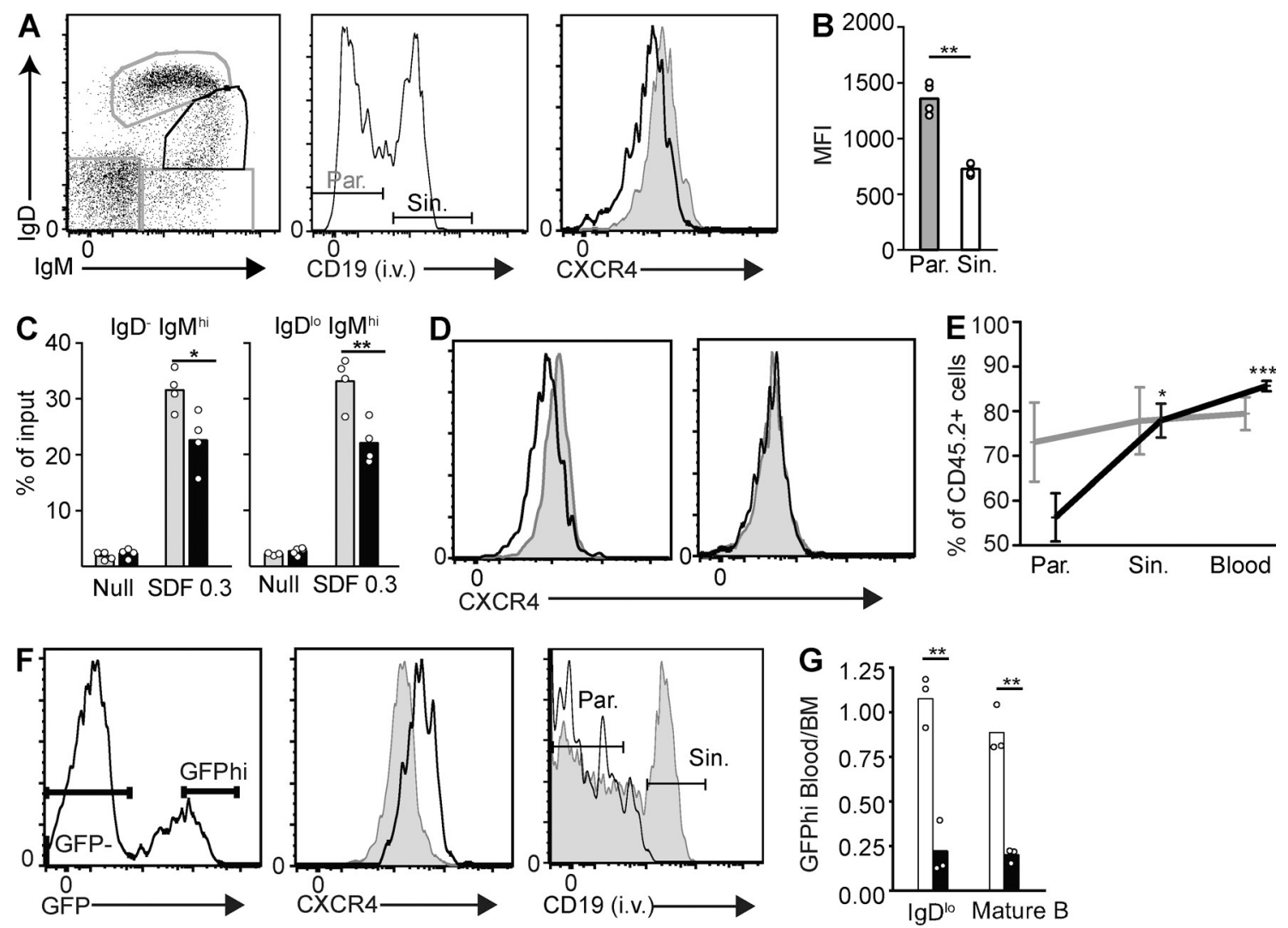

Figure 5. CXCR4 expression in egress-competent immature B lymphocytes. (A) CXCR4 expression in B220+ immature $\lg M^{+} \lg D^{\circ} B$ cells positioned in BM parenchyma (Par.) and sinusoids (Sin.). (left) IgM and IgD expression in B220+ BM cells. (middle) Distribution of B220+ $\mathrm{CD}^{+} 3^{+} \lg \mathrm{M}^{+} \lg \mathrm{D}^{\circ} \mathrm{B}$ cells in

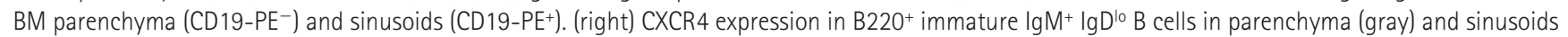
(black line). (B) Geometric mean fluorescence intensity (MFI) of CXCR4 surface expression in BM parenchyma and sinusoid immature $\mathrm{CD} 3^{+}$IgM ${ }^{+}$IgD ${ }^{10}$ B cells from C57BL/6 mice $(n=4)$. Bars indicate the mean; circles indicate individual mice. Data are representative of $>10$ independent experiments.

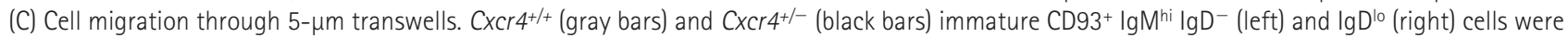
allowed to migrate toward $0.3 \mu \mathrm{g} / \mathrm{ml} \mathrm{CXCL12}$ for $3 \mathrm{~h}$. Bars indicate mean, and circles indicate replicates. Data were pooled from two independent ex-

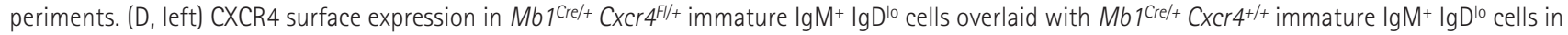

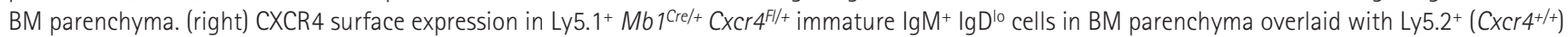
immature $\lg \mathrm{M}^{+} \lg \mathrm{D}^{10}$ cells residing in sinusoids. (E) Distribution of $\mathrm{B}_{22} 2 \mathrm{O}^{+} \mathrm{CD} 3^{+} \lg \mathrm{M}^{+} \lg \mathrm{D}^{10}$ immature $\mathrm{B}$ cells in BM parenchyma, sinusoids, and PB of le-

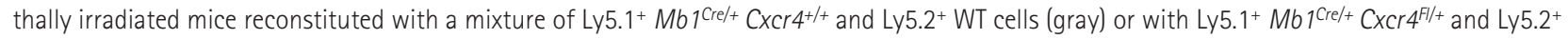
WT cells (black). Error bars indicate \pm SEM. (F) Overexpression of truncated CXCR4 (R334X WHIM mutation) in BM cell subsets reported by GFP expression. (left) GFP expression in gated $\mathrm{B} 220^{+} \mathrm{CD}^{+} 3^{+} \mathrm{lgM} \mathrm{M}^{+} \mathrm{IgD} \mathrm{D}^{10}$ immature B cells. (middle) CXCR4 surface expression in gated GFP- (gray) and GFP+ (black line)

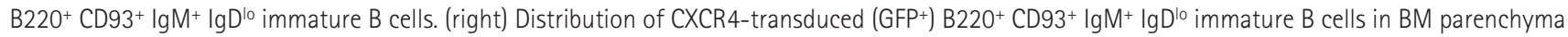
and sinusoids. (G) Ratio of the frequencies of GFPhi immature $\mathrm{lg} \mathrm{D}^{10}$ and mature $\mathrm{B}$ cells in PB and in BM. Bars indicate mean; circles indicate individual mice. Data were pooled from three independent experiments. ${ }^{*}, \mathrm{P}<0.05 ;{ }^{* *}, \mathrm{P}<0.005 ;{ }^{* * *}, \mathrm{P}<0.0005$ by unpaired Student's $t$ test.

BM egress and found that it was reduced by approximately twofold in cells within sinusoids as compared with cells in parenchyma (Fig. 5, A and B). This reduction was evident even after treatment with AMD3100 (not depicted), suggesting that it was not mediated by CXCR4 desensitization from exposure to perisinusoidal sources of CXCL12 (Ding and Morrison, 2013). A twofold reduction in CXCR 4 was sufficient to reduce immature B lymphocyte migration toward a gradient of CXCL12 established in vitro (Fig. 5 C). To test whether a twofold down-regulation of CXCR 4 was sufficient to mobilize immature B cells from BM, we compared the distribution of CXCR 4 heterozygous B lineage cells in direct competition with CXCR4 WT cells in BM parenchyma, sinusoids, and PB.
To accomplish this, we reconstituted lethally irradiated mice with a $50 \%$ mixture of BM cells isolated from $\mathrm{Cxcr} 4^{+/-}$or Cxcr4 $4^{+/+}$CD 45.1 mice with $\mathrm{CxCr} 4^{+/+} \mathrm{CD} 45.2$ mice. As expected, $\mathrm{CxCr} 4^{+/-}$immature B cells in BM parenchyma expressed comparable CXCR4 surface amounts as $\mathrm{Cxcr} 4^{+/+} \mathrm{B}$ cells positioned within BM sinusoids, whereas $\mathrm{Cxcr} 4^{+/-}$immature B cells expressed approximately twofold lower CXCR 4 than Cxcr4 $4^{+/+}$immature B cells in BM parenchyma (Fig. 5 D). Furthermore, $\mathrm{Cxcr} 4^{+/-}$immature B cells were significantly reduced in BM parenchyma and increased in BM sinusoids and blood when compared with Cxcr $4^{+/+}$immature B cells (Fig. 5 E). Antagonizing CXCR 4 down-regulation by retroviral transduction of hematopoietic stem cells with a desensitization-deficient 
CXCR 4 (R334X mutation that causes the WHIM syndrome in humans [Hernandez et al., 2003]) was sufficient to prevent immature B lymphocyte egress from BM parenchyma into sinusoids and into PB (Fig. 5, F and G).

\section{BCR signaling antagonizes CXCR4 down-regulation in immature $B$ cells and prevents BM egress}

In late stages of B cell development, newly generated immature B cells undergo negative selection against systemic selfantigens predominantly in BM (Goodnow et al., 2005). This process is likely promoted by immature B cell migration within BM by facilitating cellular interactions and screening for self-reactive BCRs. As B lineage cell migration in BM is controlled by CXCR 4 and reduced CXCR 4 signaling is essential for BM export, we hypothesized that BCR signaling intensity controlled CXCR 4 expression in immature B cells. To test this hypothesis, we analyzed CXCR 4 surface expression in immature B cells before and after inducing BCR stimulation. For this purpose, we isolated BM cells from WT mice (C57BL/6), MD4 BCR transgenic mice (B cells specifically recognize hen egg lysozyme [HEL]), and B1-8 BCR transgenic mice (nitrophenyl hapten-specific B cells) and induced BCR signaling with cognate antigens for various periods of time. We found that immature B cells increased CXCR 4 surface expression as early as $3 \mathrm{~h}$ after treatment with stimulatory anti-IgM antibodies or with cognate antigens and peaked at $12 \mathrm{~h}$ after BCR stimulation (Fig. 6, A and B). We then asked whether self-antigen engagement was sufficient to prevent immature B cell egress from BM. We treated MD4 transgenic mice with $10 \mathrm{mg}$ HEL for $6 \mathrm{~h}$ i.v. and measured immature $\mathrm{B}$ cell subsets in BM parenchyma, sinusoids, and PB. We found that HEL treatment not only significantly increased CXCR 4 expression in immature B cells in vivo (Fig. $6 \mathrm{C}$ ), but also prevented immature B lymphocyte egress into sinusoids and PB by almost 10-fold (Fig. 6, D and E). The effects of HEL on CXCR 4 expression and B cell egress blockade were strictly dependent on an HEL-specific BCR (Fig. 6 F). The peripheral reduction in immature $B$ lymphocyte subsets was not caused by BCR signaling-induced cell death because these cells significantly accumulated in BM parenchyma (Fig. 6 E). Furthermore, similar results were obtained with MD4 immature B lymphocytes that overexpressed antiapoptotic BCL2 (Fig. $6 \mathrm{H}$ ). These results predicted that antigen engagement altered B lineage cell movement in BM parenchyma. To test this hypothesis, we crossed MD4 BCR transgenic mice with mice expressing cre recombinase driven by $C d 19$ and with mice encoding the ZsGreen fluorescent protein driven by the chicken albumin and rabbit $\beta$ globin promoter within the Rosa26 locus, preceded by a premature transcriptional stop codon flanked by loxP sites (for simplicity referred as Rosa $26^{\text {ZsGreen/+}}$; Madisen et al., 2010). Using this strategy, 99\% of ZsGreen ${ }^{+}$cells were $\mathrm{IgM}^{+} \mathrm{B}$ lineage cells (not depicted). We lethally irradiated C57BL/6 recipient mice and reconstituted them with BM cells taken from $\mathrm{MD}^{+}$and $\mathrm{MD}^{-} \mathrm{Cd} 19^{\mathrm{Cre} /+}$ Rosa $26^{\mathrm{ZsGren} /+}$ mice. To measure the effect of antigen engagement mostly in immature B lymphocyte motility in BM, we analyzed the calvaria of
BM chimeras by IVM 4 wk after reconstitution, a time point where $\sim 75 \%$ of $\mathrm{ZsGreen}^{+} \mathrm{B}$ lineage cells were immature B lymphocytes, as measured by CD93 surface expression (not depicted). In agreement with these findings, the amoeboid polarity and motility of $\mathrm{MD}^{+} \mathrm{B}$ lymphocytes increased significantly after exposure to HEL, whereas the movement and morphology of MD4 ${ }^{-} \mathrm{B}$ lineage cells was unaffected by HEL treatments (Fig. 6, I and J). We also noted that $\mathrm{MD}^{+} \mathrm{B}$ cells were less motile and more rounded than $\mathrm{MD}^{-} \mathrm{B}$ cells (Fig. 6, I and J). However, this difference was likely caused by the very limited size of pro-B and pre-B cell compartment in MD4 transgenic mice as compared with that in WT mice (not depicted). In summary, these data demonstrate that immature B cell motility and retention within BM parenchyma are significantly increased by BCR signaling.

\section{DISCUSSION}

Recent studies provided substantial mechanistic insight into the multistep process of lymphocyte egress from secondary lymphoid organs: as B and T lymphocytes randomly move via the activity of distinct chemoattractants, lymphocytes make frequent contacts and probe lymphoid organ sinuses. The availability of the egress-promoting chemoattractant S1P, presumably at sinusoidal exit sites, and signaling through the lymphocyteintrinsic PTX-sensitive $\mathrm{S}_{\mathrm{PR}}$ are both required for lymphocyte reverse transmigration across sinusoidal endothelium and egress (Cyster and Schwab, 2012). Here, we demonstrate that developing B cell retention in BM parenchyma was dependent on lymphocyte-intrinsic amoeboid motility, predominantly mediated by CXCR 4 signaling and by $\alpha 4 \beta 1-V C A M-1$. However, BM egress was surprisingly independent of egresspromoting chemoattractants sensed by PTX-sensitive GPCRs. PTX treatments in vivo have been shown to mobilize B cells and hematopoietic stem/progenitor cells from BM (Papayannopoulou et al., 2003; Ueda et al., 2004). In the work presented here, we now show that cell-intrinsic PTX expression not only reduces B lineage cell movement within BM parenchyma, but also mobilizes B lineage cells, NK cells, monocytes, and granulocytes from BM into the periphery.

The immature B cell stage is characterized by a significant change in positioning within BM, with up to $50 \%$ of immature $\mathrm{B}$ cells localizing within BM sinusoids in an $\alpha 4 \beta 1-V C A M-1-$ and $\mathrm{CB} 2$ and $\mathrm{S}_{1} \mathrm{PR}_{3}$ signaling-dependent manner (Pereira et al., 2009; Donovan et al., 2010). However, immature B cell movement toward sinusoids was independent of CB2- and $\mathrm{S}_{1} \mathrm{PR}_{3}-$ mediated chemotaxis and only partially contributed by S1P and S1PR ${ }_{1}$ (Allende et al., 2010; Pereira et al., 2010). Our experiments now reveal that CXCR 4 down-regulation enforced $\mathrm{B}$ cells to distribute into perisinusoidal and intrasinusoidal compartments and was critical for immature B cell egress from BM. Furthermore, these experiments also suggest that $\alpha 4 \beta 1-$ mediated adhesion is temporally reduced when cells are in perisinusoidal compartments, before it is increased again within sinusoids, likely through CB2-induced transactivation (Pereira et al., 2009). It is possible that B cell-intrinsic $\alpha 4 \beta 1$ andVCAM-1 expressed on sinusoidal endothelial cells may antagonize reverse 

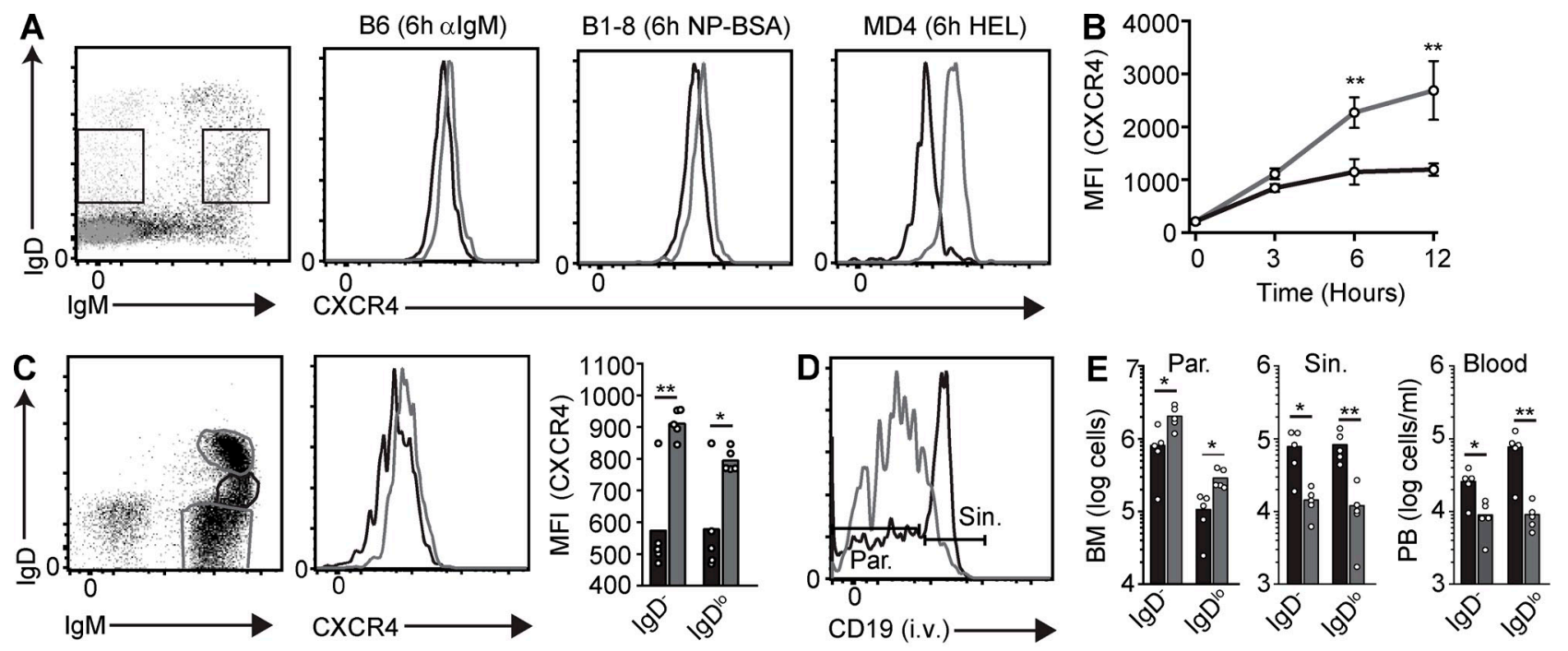
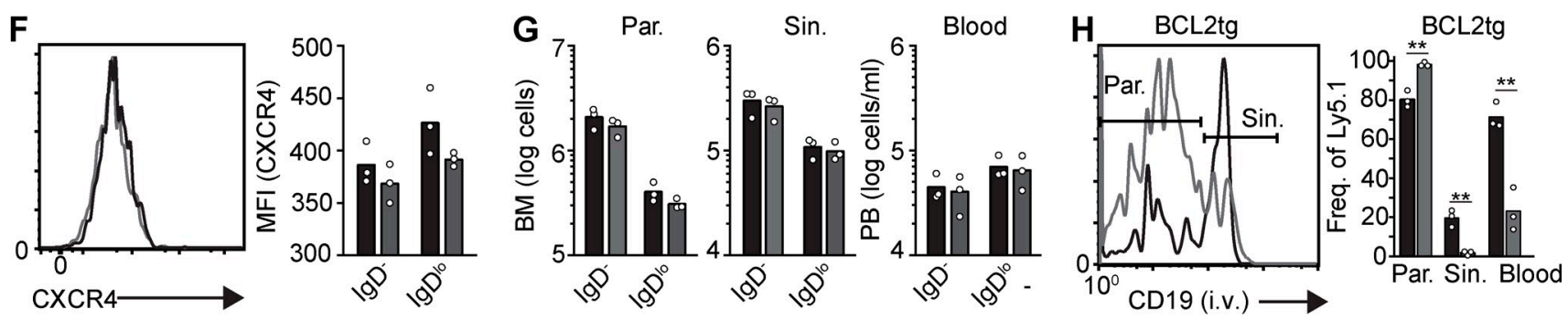

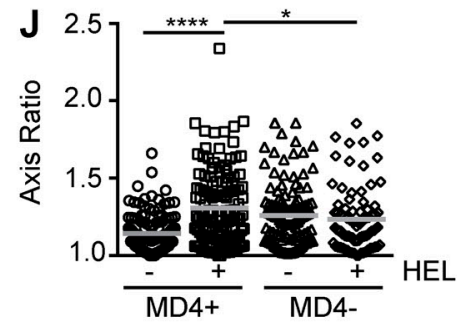

Figure 6. BCR signaling increases CXCR4 expression, promotes $B$ lymphocyte motility, and prevents BM egress. (A) $\lg M$ and $\lg D$ expression in unstimulated and BCR-stimulated B220+ cells (left and right gates, respectively). (B) CXCR4 mean fluorescence intensity (MFI) in $\operatorname{lgM}{ }^{+} \lg D^{10}$ CD93 $3^{+}$MD4 $B$ cells untreated (black) or stimulated with $1 \mathrm{mg} / \mathrm{ml} \mathrm{HEL} \mathrm{(gray)} \mathrm{for} \mathrm{the} \mathrm{indicated} \mathrm{time} \mathrm{periods.} \mathrm{Lines} \mathrm{indicate} \mathrm{mean}( \pm S E M)$ of three independent experiments. (C) CXCR4 surface expression in unstimulated (black) and in vivo HEL-stimulated (6 h; gray) immature (CD93+) MD4 B cell subsets. (D) MD4 immature $\lg \mathrm{M}^{+} \operatorname{Ig} \mathrm{D}^{10} \mathrm{CD} 3^{+} \mathrm{B}$ cell distribution in BM before and after HEL i.v. treatment for $6 \mathrm{~h}$. (E) Quantification of immature $\mathrm{B}$ cell subsets in BM parenchyma (Par.), sinusoids (Sin.), and PB of MD4 mice treated with HEL for $6 \mathrm{~h}$. (F) CXCR4 surface expression in WT immature $\operatorname{lgM}{ }^{+} \lg D^{10} \mathrm{CD}^{+} 3^{+} \mathrm{B}$ cells stimulated with PBS (black) or with HEL i.v. (gray). (right) CXCR4 MFI on unstimulated (black) and HEL-stimulated (gray) immature $\operatorname{lgM}{ }^{+} \lg D^{10} \mathrm{CD} 3^{+}$ B cells from WT mice. (G) Quantification of immature B cell subsets in BM parenchyma, sinusoids, and PB of WT mice treated with HEL for 6 h. (H, left) Distribution of immature $\lg \mathrm{M}^{+} \lg \mathrm{D}^{10} \mathrm{CD} 93^{+} \mathrm{MD} 4 \mathrm{~B}$ cells overexpressing $\mathrm{Bc} / 2$ in $\mathrm{BM}$ parenchyma (CD19-PE-) and in sinusoids (CD19-PE+). (right) Immature $\mathrm{CD}_{3}{ }^{+} \operatorname{lgM}{ }^{+} \lg \mathrm{D}^{10} \mathrm{~B}$ cell numbers in BM parenchyma, sinusoids, and PB of MD4.BCL2 transgenic mice treated with $\mathrm{HEL}$. (E, $\mathrm{G}$, and $\left.\mathrm{H}\right) \mathrm{Bars}$ indicate mean, and circles depict individual mice. Data are representative of two independent experiments. (I) Mean motility coefficient of MD4+ and MD4 ${ }^{-}$Cd19Cre/ + Rosa26 $6^{\mathrm{sG}} \mathrm{reen} /+\mathrm{B}$ lineage cells before and $6 \mathrm{~h}$ after treatment with HEL i.v. Lines depict the average mean motility coefficient calculated from datasets obtained by IVM of two to three mice. (J) Axis ratio (x/y) of MD4+ and MD4 ${ }^{-}$Cd19cre/+ Rosa26 $6^{2 s G r e e n /+} \mathrm{B}$ lineage cells before and $6 \mathrm{~h}$ after $\mathrm{HEL}$ treatment i.v. Circles, unstimulated MD4+ B cells; squares, HEL-stimulated MD4+ B cells; triangles, HEL-stimulated MD4- B cells; diamonds, MD4- unstimulated B cells. Lines indicate mean. Data are representative of three independent experiments. ${ }^{*}, \mathrm{P}<0.05 ;{ }^{* *}, \mathrm{P}<0.005 ;{ }^{* * * *}, \mathrm{P}<0.00005$ by unpaired Student's $t$ test.

transmigration of developing B cell subsets and prevent their egress from BM. However, conditional deletion of VCAM-1 from endothelial (and hematopoietic) cells induced the selective mobilization of immature B cell subsets, most prominently immature $\operatorname{IgM}^{+} \operatorname{IgD}^{\text {lo }}$ cells (which are distributed between BM parenchyma and sinusoids), without significant effects measured in parenchyma-restricted pro-B and pre-B cell subsets (Koni et al., 2001). Thus, these data are in agreement with the finding that $\alpha 4 \beta 1-V C A M-1$ is specifically required for sinusoidal retention (Pereira et al., 2009) and disfavor a prominent role played by $\alpha 4 \beta 1-V C A M-1$ in impeding migration across sinusoidal endothelium. 
Immature B cells egress BM by down-regulating CXCR 4 by approximately twofold through a mechanism that was antagonized by antigen-induced BCR signaling, presumably after negative selection has occurred. In vitro studies using mouse primary immature B cells and a chicken B cell line reported that antigen-induced BCR signaling reduced $\mathrm{B}$ cell chemotaxis toward CXCL12, while having no detectable effect on CXCR4 surface expression (Guinamard et al., 1999; Brauweiler et al., 2007). Here, using two independent BCR transgenic mouse strains and WT (polyclonal) mice, we reliably measured BCR-induced CXCR 4 expression in immature $\mathrm{B}$ cells in vitro and in vivo and a corresponding increase in B lineage interstitial motility and retention within BM parenchyma. The discrepancy between these findings could be related to an inadequacy of the in vitro systems for measuring antigen-coated immature B cell chemotaxis. However, our experiments are consistent with the observation that CXCR 4 expression was increased in immature B cells in multiple murine models of lupus (Wang et al., 2009a), given that these cells encounter self-antigens during development in BM ( $\mathrm{Li}$ et al., 2002). It will be valuable to analyze the cellular composition and biological significance of the BM niches that attract self-reactive immature B cells.

Even though the S1P pathway contributes to promote hematopoietic cell egress from BM, namely NK cells, monocyte/osteoclast precursors, eosinophils, and immature B cells (Walzer et al., 2007; Jenne et al., 2009; Allende et al., 2010; Pereira et al., 2010; Sugita et al., 2010), its relatively minor contribution is in agreement with a marginally detectable S1P gradient between BM parenchyma and sinusoids (Jenne et al., 2009). The BM sinusoids are fenestrated and allow passive flow of circulatory fluids into the parenchyma (Tavassoli and Yoffey, 1983; Mazo et al., 1998). Interestingly, the few observed examples of B lineage cell egress from BM parenchyma into sinusoids occurred exclusively in areas where vascular leakage was readily observed. This observation raises the possibility that $\mathrm{S} 1 \mathrm{P}$ receptors promote $\mathrm{BM}$ egress from areas in parenchyma that are less perfused. Whether the fenestrated nature of the BM sinusoidal endothelium is a constitutive feature or a regulated process remains unknown.

The mechanical forces responsible for purging sessile B cells from BM are not entirely clear, but such mechanisms likely promote the egress of other hematopoietic cell subsets, including poorly motile red blood cells. The dependency on integrin-mediated adhesion for motility in BM demonstrates that developing B cells adopt similar mechanisms to those used by leukocytes during migration on luminal endothelial surfaces under shear stress generated by blood flow (Alon and Feigelson, 2009). The sudden morphological changes observed immediately after CXCR 4 and/or $\alpha 4$ integrin blockade are also reminiscent of the cell shape changes seen in $\mathrm{T}$ cells exposed to lymph flow in lymphatic sinuses (Grigorova et al., 2009). Immature B cells likely adapted to haptokinetic migration for retention and controlled migration in shear-rich threedimensional environments such as BM, and possibly the spleen. Consistent with this model, marginal zone $\mathrm{B}$ cells move between blood-bathed splenic red pulp and bloodless follicles in the white pulp and also rely on integrin-mediated adhesion for their retention in this compartment (Arnon et al., 2013). The observation that B lineage cell exit occurred from areas of intense parenchymal perfusion, and that several B cells were largely nonmotile and remained rounded during reverse transmigration, suggests that drainage of interstitial fluids back into circulation via collecting sinusoids facilitates BM export of B lineage cells and possibly other hematopoietic cell types, including red blood cells. In agreement with this model, neutrophils are also poorly motile in BM and are stationed near or at BM exit sites for several minutes before exiting into the sinusoidal lumen (Devi et al., 2013).

Whereas CXCR4-deficient pro-B and pre-B cells were easily detected in blood and spleen, as expected (Ma et al., 1999; Ueda et al., 2004), their numbers in BM were only slightly reduced when compared with immature B cell subsets. These data indicate that early B cell subsets are less efficiently mobilized from BM than immature B cells and suggest that they use other retention mechanisms. However, the majority of $\mathrm{GFP}^{+} \mathrm{B}$ lineage cells (which include pro-B and pre-B cells) remained predominantly sessile, exhibited a rounded morphology, and seemed largely nonadherent to the extracellular matrix when they lacked $\alpha 4 \beta 1-$ mediated adhesion to VCAM-1. An alternative and attractive possibility is that pro-B and pre-B cells cannot undergo efficient reverse transmigration. Electron microscopy studies of femoral marrow of rats, rabbits, and guinea pigs documented extensive evidence of intimate interactions between immature lymphocyte pseudopodia and cell processes between adjacent sinusoidal endothelial cells (Tavassoli and Yoffey, 1983). In some instances, though not infrequent, lymphocyte pseudopodia were seen extending through endothelial cells (Hudson and Yoffey, 1966). We also observed few examples of WT and PTX-expressing B cells elongating during reverse transmigration through sinusoids. These observations suggest that reverse transmigration across some areas of the sinusoidal endothelial wall requires an active process. Our study reveals that it is independent of GPCR signaling.

Thymocyte egress is directly linked to TCR signaling intensity through AKT/FOXO1 inhibition of KLF2-dependent S1PR $_{1}$ expression (Hart et al., 2012), which likely prevents premature egress of autoreactive $\mathrm{T}$ lymphocytes (Zachariah and Cyster, 2010). Similarly, immature B lymphocyte egress is sensitive to BCR signaling intensity as it controlled CXCR 4 expression. However, even when CXCR 4 was overexpressed in developing B cells, a few immature B cells expressing high amounts of CXCR 4 were detected in blood and spleen. Likewise, small numbers of B cells and neutrophils can be found in PB of WHIM patients, in which CXCR 4 is constitutively active because of mutations that prevent its desensitization. Finally, autoreactive immature B cells can still egress from mouse and human BM, albeit inefficiently (Hartley et al., 1993; Wardemann et al., 2003). Combined, these data suggest that the BM architecture and its fenestrated vasculature generate a cell egress-permissive environment that contrasts with rather impermeable egress sites from the thymus. We suggest 
that the passive mode of leukocyte egress from BM evolved to facilitate the release of highly heterogeneous leukocyte subsets that include nonmotile cells, at the expense of some premature exit of developing B lymphocytes. This fundamental difference between $\mathrm{T}$ and $\mathrm{B}$ lymphocyte egress strategies from primary lymphoid organs possibly imposed an evolutionary pressure for additional extramedullary B cell developmental checkpoints (Carsetti et al., 2004).

\section{MATERIALS AND METHODS}

Mice. Adult C57BL/6 (CD45.2), Boy/J (CD45.1), Itgb1 $1^{\mathrm{Fl} / \mathrm{Fl}}, \mathrm{Lyz} 2^{\mathrm{Cre} /+}$, Cd19Gre/+ and Rosa26 $6^{\text {FloxSTOP-ZsGren/+ }}$ (Madisen et al., 2010) mice were from obtained from The Jackson Laboratory. MD4 and MD4.Bcl2 transgenic mice were from an internal colony (J.G. Cyster). B1-8 transgenic mice were provided by A. Haberman (Yale University, New Haven, CT). Cxcr $4^{F / /-}$ and Rosa $26^{\text {FloxSTOP-PTX/+ }}$ (Regard et al., 2007) mice were crossed with $M b 1^{\mathrm{Cre} /+}$ mice (Pelanda et al., 2002) to generate Cxcr $4^{\mathrm{Fl} /-} \mathrm{Mb} 1^{\mathrm{Cre} /+}$ and Rosa2 $6^{\mathrm{FloxSTOP}-\mathrm{PTX} /+}$ $M b 1^{\text {cre } /+}$ mice (all provided by J.G. Cyster). Rosa $26^{\text {FloxSTOP-PTX/+ }}$ mice were crossed to $\mathrm{Ly}_{\mathrm{z} 2 \mathrm{Crel} / \mathrm{+}}$ and $\mathrm{Il} 7 \mathrm{r}_{\mathrm{Cre} /+}$ to generate Rosa26 $6^{\mathrm{FloxSTOP}-\mathrm{PTX} /+} \mathrm{Il} 7 \mathrm{r}_{\mathrm{Cre} /+}$,

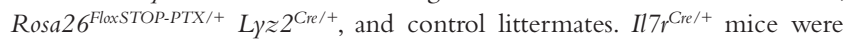
provided by H.-R. Rodewald (German Cancer Research Center, Heidelberg, Germany). For intravital imaging, $\mathrm{CXcr} 4^{\mathrm{Fl} /-}$, Itgb $1^{\mathrm{Fl} / \mathrm{Fl}}$, and Rosa $26^{\mathrm{FloxSTOP}-\mathrm{PTX} /+}$ $\mathrm{Mb}^{\mathrm{Cre} /+}$ were crossed with Rag $1^{\mathrm{GFP} /+}$ mice (Kuwata et al., 1999). Mice were maintained under specific pathogen-free conditions and used according to the protocols approved by the Yale University Institutional Animal Care and Use Committee.

Two-photon intravital imaging. Mice were anesthetized with ketamine/ xylazine and immobilized on a custom-built stage. Laser-scanning microscopy images were collected using a BX61WI fluorescence microscope (Olympus) and a $20 \times 0.95 \mathrm{NA}$ water immersion objective (Olympus) and dedicated singlebeam TriM Scope II (LaVision Biotec) controlled by IMSpector software. The microscope was outfitted with a Chameleon Vision II Ti:Sapphire laser (Coherent) with pulse precompensation. For 4D analysis of cell migration, stacks of $13-17$ optical sections with $3-\mu \mathrm{m} z$ spacing were acquired every 20 or $30 \mathrm{~s}$ for $30 \mathrm{~min}$ with the laser tuned to a wavelength of $845-875 \mathrm{~nm}$. Pharmacological antagonists AMD3100 (Tocris Bioscience), 4F-benzoyl-TN14003 (a gift from H. Tamamura, Tokyo Medical and Dental University, Tokyo, Japan), and anti-VCAM-1 (clone M/K2; Bioexpress Inc.), anti- $\alpha 4$ (clone PS/2; LygoCyte Pharma Inc.), and anti-CXCL12 (clone 79014; R\&D Systems) blocking antibodies were injected i.v. 1-5 min before imaging. Videos in which significant tissue drifting was detected were excluded from analyses. A few videos showed small tissue drifting, which was computationally corrected with Imaris software tool "Correct Drift" (Bitplane).

The axis ratio of parenchymal $\mathrm{GFP}^{+}$cells was calculated by measuring the distance between the two furthest $\mathrm{GFP}^{+}$points on the $\mathrm{x}$ and $\mathrm{y}$ planes of individual cells after collapse of the $\mathrm{z}$ plane using Imaris. Parenchymal GFP ${ }^{+}$ cells that were distinguishable from neighboring cells were selected for analysis to avoid miscalculation of the axis ratio of a single $\mathrm{GFP}^{+}$cell.

Tissue preparation, cell enumeration, and antibodies. BM cells were flushed from femurs and tibias in DMEM (Cellgro) containing 2\% FBS (Invitrogen), $5 \%$ of antibiotics (Cellgro), and Hepes (Cellgro). PB was collected from the portal vein, and erythrocytes were lysed with $\mathrm{NH}_{4} \mathrm{Cl}, \mathrm{KHCO}_{3}$, and EDTA. Spleen was dissociated in $5 \mathrm{ml}$ DMEM containing $2 \% \mathrm{FBS}, 5 \%$ of antibiotics, and Hepes using a cell strainer (Thermo Fisher Scientific). Cells were counted with a Coulter Counter (Beckman Coulter). B cells were identified by staining with anti-B220 (RA3-6B2) or CD19 (1D3), anti-IgM (11/41), anti-IgD (11-26c.2a), and anti-CD93 (AA4.1) antibodies. Monocytes and granulocytes were stained with Ly6C (HK1.4), CD11b (M1/70.15), and CD115 (AFS98) antibodies, and NK cells were stained with CD3e (1452C11) and NK1.1 (PK136) antibodies. Dead cells were excluded by staining with DAPI. Cells were analyzed by FACS (LSRII; BD).
Measurement of FITC-conjugated dextran dye perfusion into the parenchyma. Dye perfusion was measured by selecting two regions of interest in the BM parenchyma and FITC-conjugated labeled sinusoids using Imaris. A surface was applied to the green channel to generate voxels in regions of interest within the BM parenchyma and sinusoids over the course of the video. Perfusion of FITC-dextran into the parenchyma was assessed by measuring the number of voxels that appeared in the regions of interest over the course of a 29-min video.

Calculation of interstitial flow rate of dye perfusion into the BM parenchyma. Analyses of interstitial fluid flow were performed as described previously (Iliff et al., 2012; Egawa et al., 2013). In brief, flow rate within BM parenchyma was measured by injecting FITC-dextran (500 kD) or BSATexas red i.v. into anesthetized mice. Mice were then immediately imaged by two-photon IVM. The volumetric flow rate in the BM parenchyma was quantified by first applying a surface to the appropriate channel. Next, a threedimensional box of a fixed volume was applied to three regions of interest. The instantaneous flow rates (on average six time points) of dye before the threedimensional box was filled were used to calculate the mean instantaneous flow rate. The instantaneous flow rate $\left(\mu \mathrm{m}^{3} / \mathrm{s}\right)$ was calculated by taking the difference between volumes from consecutive time points and dividing this difference by time $(60 \mathrm{~s})$.

In vivo labeling of $\mathrm{BM}$ sinusoidal $\mathrm{B}$ cell subsets. $\mathrm{BM}$ sinusoidal cells were labeled by injecting i.v. $0.3 \mu \mathrm{g}$ phycoerythrin-conjugated rat antimouse CD19 (1D3) in $200 \mu$ PBS. 2 min after, mice were sacrificed in a $\mathrm{CO}_{2}$ chamber.

BrdU and PTX treatment. Mice were treated with $1 \mathrm{mg} / \mathrm{ml} \mathrm{BrdU}(\mathrm{BD})$ i.v. and administered $1 \mathrm{mg} / \mathrm{ml} \mathrm{BrdU}$ (Sigma-Aldrich) in drinking water $24 \mathrm{~h}$ before analysis. $1 \mu \mathrm{g}$ PTX (List Bio Labs) was injected i.v. $24 \mathrm{~h}$ before analysis. BrdU-labeled cells were identified staining with anti-BrdU FITC according to the manufacturer's protocol. B cells were identified by staining with antiB220 (RA3-6B2) or CD19 (ebio1D3), anti-IgM (11/41), anti-IgD (11-26.c.2a), and anti-CD93 (AA4.1). Monocytes, NK cells, and granulocytes were identified by staining for anti-Ly6c (HK1.4), anti-CD11b (M1/70), anti-CD3 $\varepsilon$ (145-2C11), anti-NK1.1 (PK136), and anti-CD115 (AFS98). After staining, cells were analyzed by FACS (LSRII).

BM chimeras. Approximately $1.5 \times 10^{6}$ total $\mathrm{BM}$ cells from Ly5.1+ donors were mixed with $1.5 \times 10^{6}$ total BM cells from adult Boy/J $\left(\mathrm{Ly} 5.2^{+}\right)$mice and were transferred into adult Boy/J mice that had been exposed to two rounds of 6.35 Gy separated by $3 \mathrm{~h}$. Chimeras were analyzed at least $6 \mathrm{wk}$ after reconstitution.

Transwell migration assays. Chemotaxis assays were performed using $10^{6}$ $\mathrm{BM}$ or spleen cells incubated for 30 min with $1 \times$ DMEM containing $0.5 \%$ fatty acid-free BSA (EMD Biosciences), 5\% of antibiotics, L-glutamine (Cellgro), and Hepes. Cells were then allowed to migrate through $5-\mu \mathrm{m}$-poresized transwells (Corning) toward soluble CXCL12 (R\&D Systems), 2-AG (Cayman), or CXCL13 (PeproTech) for $3 \mathrm{~h}$ at $37^{\circ} \mathrm{C}$. Cells were collected, stained, and resuspended in $40 \mathrm{ml}$ of staining buffer and analyzed by flow cytometry for $40 \mathrm{~s}$.

Retroviral BM transduction. The R334X mutation in CXCR 4 cytoplasmic tail was cloned into mammalian retroviral vector (pMSCV) upstream of an IRES-truncated GFP cassette as a reporter. Sanger DNA sequencing reaction verified truncated CXCR4 sequences. Phoenix 293T cells were transfected with MSCV retroviral constructs with Lipofectamine 2000 (Invitrogen) according to the manufacturer's protocol. For mutant Cxcr4 (R33x) transduction of hematopoietic stem cells, BM cells were harvested $5 \mathrm{~d}$ after i.p. injection of 5-fluoracil (Sigma-Aldrich) and cultured with IL-3, IL-6, and $100 \mathrm{ng} / \mathrm{ml} \mathrm{mSCF}$ (PeproTech). BM cells were then spin-infected twice with a retroviral constructs and injected i.v. into lethally irradiated Boy/J recipients. Mice were analyzed at least $5 \mathrm{wk}$ after reconstitution. 
In vitro antagonist treatments. $10^{6} \mathrm{BM}$ or spleen cells were treated with saline $(0.9 \% \mathrm{NaCl})$ or $\mathrm{AMD} 3100$ for $1 \mathrm{~h}$ at $37^{\circ} \mathrm{C}$. Cells were then removed from incubation and used in transwell migration assays.

BCR stimulations in vivo and in vitro. BM cells isolated from femurs and tibias were prepared at $10^{7}$ cells $/ \mathrm{ml}$ in DMEM containing $10 \% \mathrm{FBS}$, $10 \mathrm{mM}$ Hepes, and a cocktail of penicillin and streptomycin $(50 \mathrm{U} /$ liter and $50 \mu \mathrm{g} /$ liter, respectively). Approximately $2 \times 10^{6}$ cells were left unstimulated or stimulated with $20 \mu \mathrm{g} / \mathrm{ml} \mathrm{F}\left(\mathrm{ab}^{\prime}\right) 2$ fragment goat anti-mouse IgM (Jackson ImmunoResearch Laboratories, Inc.), with $20 \mu \mathrm{g} / \mathrm{ml}$ HEL (Sigma-Aldrich), or with $1 \mathrm{mg} / \mathrm{ml} \mathrm{NP-BSA} \mathrm{(Biosearch} \mathrm{Technologies,} \mathrm{Inc.),} \mathrm{at} 37^{\circ} \mathrm{C}$ and $5 \%$ $\mathrm{CO}_{2}$ for the indicated time points in the Fig. 6 legend.

MD4 and MD4.Bcl2 transgenic mice were stimulated with $10 \mathrm{mg}$ HEL for $6 \mathrm{~h}$. Mice were injected with $0.3 \mu \mathrm{g}$ phycoerythrin-conjugated rat antimouse CD19 (1D3) in $200 \mu \mathrm{l}$ PBS before sacrifice. Cells isolated from femur and tibia BM, PB (portal vein), and spleen were counted in a Coulter Counter and stained to detect B cell subsets, as previously described in Tissue preparation, cell enumeration, and antibodies.

Statistics. Student's two-tailed $t$ test or $\chi^{2}$ test was performed using GraphPad Software Prism 6 or Microsoft Excel. A value $<0.05$ was considered significant.

Online supplemental material.Video 1 shows intravital imaging of developing B cell migration before and after treatment with AMD3100 (25 min). Video 2 shows intravital imaging of Cxcr4-deficient developing B cell migration (30 min).Video 3 shows intravital imaging of Cxcr4-deficient developing B cell migration before and after treatment with AMD3100 (30 min).Video 4 shows intravital imaging of developing $\mathrm{B}$ cell migration before and after treatment with anti-VCAM-1 (30 min).Video 5 shows intravital imaging of Itgb1-deficient developing B cell migration (30 min).Video 6 shows intravital imaging of developing $\mathrm{B}$ cell migration before and after treatment with antiVCAM-1 (30 min). Video 7 shows intravital imaging of FITC-conjugated dextran perfusion into the BM parenchyma $(29 \mathrm{~min})$.Video 8 shows intravital imaging of PTX-expressing B lineage cell migration in BM (30 min).Video 9 shows intravital imaging of motile PTX-expressing B lineage cell migration in BM (30 min).Video 10 shows intravital imaging of WT and PTX-expressing $\mathrm{B}$ lineage cell egress from BM. Online supplemental material is available at http://www.jem.org/cgi/content/full/jem.20140457/DC1.

We thank Dr. Heins-Reimer Rodewald for sharing II7racre/+ mice. We thank Flavia 0. Pinho (Yale University, New Haven, CT) for technical assistance with retroviral DNA constructs, Dr. Hirokazu Tamamura for 4F-benzoyl-TN14003, and David Gonzalez and Ann Haberman (Yale University) for assistance with the two-photon microscopy. We are grateful to S.R. Schwab (New York University, New York, NY) and M. Carmona (Yale University) for critical reading of the manuscript.

T.C. Beck is the recipient of a predoctoral National Science Foundation fellowship; A.C. Gomes is supported by a predoctoral fellowship from the Foundation for Science and Technology, Ministry of Education, Portugal. This work was partially supported by the National Institutes of Health (grants R56Al098996 and R01Al113040).

The authors declare no competing financial interests.

\section{Submitted: 10 March 2014}

Accepted: 31 October 2014

\section{REFERENCES}

Allende, M.L., G. Tuymetova, B.G. Lee, E. Bonifacino,Y.P.Wu, and R.L. Proia. 2010. S1P1 receptor directs the release of immature B cells from bone marrow into blood. J. Exp. Med. 207:1113-1124. http://dx.doi.org/10 $.1084 / \mathrm{jem} .20092210$

Alon, R., and S.W. Feigelson. 2009. Chemokine signaling to lymphocyte integrins under shear flow. Microcirculation. 16:3-16. http://dx.doi.org/10.1080/ 10739680802026076

Arnon, T.I., R.M. Horton, I.L. Grigorova, and J.G. Cyster. 2013. Visualization of splenic marginal zone B-cell shuttling and follicular B-cell egress. Nature. 493:684-688. http://dx.doi.org/10.1038/nature11738
Bai, A., H. Hu, M. Yeung, and J. Chen. 2007. Kruppel-like factor 2 controls $\mathrm{T}$ cell trafficking by activating L-selectin (CD62L) and sphingosine-1phosphate receptor 1 transcription. J. Immunol. 178:7632-7639. http:// dx.doi.org/10.4049/jimmunol.178.12.7632

Bernardini, G., G. Sciumè, D. Bosisio, S. Morrone, S. Sozzani, and A. Santoni. 2008. CCL3 and CXCL12 regulate trafficking of mouse bone marrow NK cell subsets. Blood. 111:3626-3634. http://dx.doi.org/10.1182/blood2007-08-106203

Brauweiler,A., K. Merrell, S.B. Gauld, and J.C. Cambier. 2007. Cutting Edge: Acute and chronic exposure of immature $\mathrm{B}$ cells to antigen leads to impaired homing and SHIP1-dependent reduction in stromal cell-derived factor-1 responsiveness. J. Immunol. 178:3353-3357. http://dx.doi.org/10.4049/ jimmunol.178.6.3353

Broxmeyer, H.E., C.M. Orschell, D.W. Clapp, G. Hangoc, S. Cooper, P.A. Plett, W.C. Liles, X. Li, B. Graham-Evans, T.B. Campbell, et al. 2005. Rapid mobilization of murine and human hematopoietic stem and progenitor cells with AMD3100, a CXCR4 antagonist. J. Exp. Med. 201:1307-1318. http://dx.doi.org/10.1084/jem.20041385

Carlson, C.M., B.T. Endrizzi, J. Wu, X. Ding, M.A. Weinreich, E.R. Walsh, M.A.Wani, J.B. Lingrel, K.A. Hogquist, and S.C. Jameson. 2006. Kruppellike factor 2 regulates thymocyte and T-cell migration. Nature. 442:299302. http://dx.doi.org/10.1038/nature04882

Carsetti, R., M.M. Rosado, and H.Wardmann. 2004. Peripheral development of B cells in mouse and man. Immunol. Rev. 197:179-191. http://dx.doi .org/10.1111/j.0105-2896.2004.0109.x

Cinamon, G., M.A. Zachariah, O.M. Lam, F.W. Foss Jr., and J.G. Cyster. 2008. Follicular shuttling of marginal zone B cells facilitates antigen transport. Nat. Immunol. 9:54-62. http://dx.doi.org/10.1038/ni1542

Clausen, B.E., C. Burkhardt, W. Reith, R. Renkawitz, and I. Förster. 1999. Conditional gene targeting in macrophages and granulocytes using LysMcre mice. Transgenic Res. 8:265-277. http://dx.doi.org/10.1023/A: 1008942828960

Cyster, J.G., and S.R. Schwab. 2012. Sphingosine-1-phosphate and lymphocyte egress from lymphoid organs. Annu. Rev. Immunol. 30:69-94. http:// dx.doi.org/10.1146/annurev-immunol-020711-075011

Devi, S., Y. Wang, W.K. Chew, R. Lima, N. A-González, C.N. Mattar, S.Z. Chong, A. Schlitzer, N. Bakocevic, S. Chew, et al. 2013. Neutrophil mobilization via plerixafor-mediated CXCR 4 inhibition arises from lung demargination and blockade of neutrophil homing to the bone marrow. J. Exp. Med. 210:2321-2336. http://dx.doi.org/10.1084/jem.20130056

Ding, L., and S.J. Morrison. 2013. Haematopoietic stem cells and early lymphoid progenitors occupy distinct bone marrow niches. Nature. 495:231235. http://dx.doi.org/10.1038/nature11885

Donovan, E.E., R. Pelanda, and R.M. Torres. 2010. S1P3 confers differential $\mathrm{S} 1 \mathrm{P}$-induced migration by autoreactive and non-autoreactive immature $\mathrm{B}$ cells and is required for normal B-cell development. Eur. J. Immunol. 40:688-698. http://dx.doi.org/10.1002/eji.200939858

Eash, K.J., A.M. Greenbaum, P.K. Gopalan, and D.C. Link. 2010. CXCR2 and CXCR 4 antagonistically regulate neutrophil trafficking from murine bone marrow. J. Clin. Invest. 120:2423-2431. http://dx.doi.org/10 $.1172 / J C I 41649$

Egawa, G., S. Nakamizo, Y. Natsuaki, H. Doi, Y. Miyachi, and K. Kabashima. 2013. Intravital analysis of vascular permeability in mice using two-photon microscopy. Sci. Rep. 3:1932. http://dx.doi.org/10.1038/srep01932

Fabre, S., V. Lang, J. Harriague, A. Jobart, T.G. Unterman, A. Trautmann, and G. Bismuth. 2005. Stable activation of phosphatidylinositol 3-kinase in the $\mathrm{T}$ cell immunological synapse stimulates Akt signaling to FoxO1 nuclear exclusion and cell growth control. J. Immunol. 174:4161-4171. http:// dx.doi.org/10.4049/jimmunol.174.7.4161

Fabre, S., F. Carrette, J. Chen, V. Lang, M. Semichon, C. Denoyelle, V. Lazar, N. Cagnard, A. Dubart-Kupperschmitt, M. Mangeney, et al. 2008. FOXO1 regulates $\mathrm{L}-$ Selectin and a network of human $\mathrm{T}$ cell homing molecules downstream of phosphatidylinositol 3-kinase. J. Immunol. 181:2980-2989. http://dx.doi.org/10.4049/jimmunol.181.5.2980

Glodek, A.M., M. Honczarenko,Y. Le, J.J. Campbell, and L.E. Silberstein. 2003. Sustained activation of cell adhesion is a differentially regulated process in B lymphopoiesis. J. Exp. Med. 197:461-473. http://dx.doi.org/10 $.1084 / \mathrm{jem} .20021477$ 
Goodnow, C.C., J. Sprent, B. Fazekas de St Groth, and C.G.Vinuesa. 2005 Cellular and genetic mechanisms of self tolerance and autoimmunity. Nature. 435:590-597. http://dx.doi.org/10.1038/nature03724

Grigorova, I.L., S.R. Schwab, T.G. Phan, T.H. Pham, T. Okada, and J.G. Cyster 2009. Cortical sinus probing, S1P1-dependent entry and flow-based capture of egressing T cells. Nat. Immunol. 10:58-65. http://dx.doi.org/ 10.1038/ni.1682

Gubbels Bupp, M.R., B. Edwards, C. Guo, D. Wei, G. Chen, B. Wong, E. Masteller, and S.L. Peng. 2009.T cells require Foxo1 to populate the peripheral lymphoid organs. Eur. J. Immunol. 39:2991-2999. http://dx.doi.org/ 10.1002/eji.200939427

Guinamard, R., N. Signoret, M. Ishiai, M. Marsh, T. Kurosaki, and J.V. Ravetch. 1999. B cell antigen receptor engagement inhibits stromal cell-derived factor (SDF) $-1 \alpha$ chemotaxis and promotes protein kinase C (PKC)induced internalization of CXCR 4. J. Exp. Med. 189:1461-1466. (published erratum appears in J. Exp. Med. 2002. 196:871) http://dx.doi.org/ 10.1084/jem.189.9.1461

Hargreaves, D.C., P.L. Hyman, T.T. Lu, V.N. Ngo, A. Bidgol, G. Suzuki, Y.R Zou, D.R. Littman, and J.G. Cyster. 2001. A coordinated change in chemokine responsiveness guides plasma cell movements. J. Exp. Med. 194:45-56. http://dx.doi.org/10.1084/jem.194.1.45

Hart, G.T., X. Wang, K.A. Hogquist, and S.C. Jameson. 2011. Krüppel-like factor 2 (KLF2) regulates B-cell reactivity, subset differentiation, and trafficking molecule expression. Proc. Natl. Acad. Sci. USA. 108:716-721. http://dx.doi.org/10.1073/pnas.1013168108

Hart, G.T., K.A. Hogquist, and S.C. Jameson. 2012. Krüppel-like factors in lymphocyte biology. J. Immunol. 188:521-526. http://dx.doi.org/10.4049/ jimmunol.1101530

Hartley, S.B., M.P. Cooke, D.A. Fulcher, A.W. Harris, S. Cory, A. Basten, and C.C. Goodnow. 1993. Elimination of self-reactive B lymphocytes proceeds in two stages: arrested development and cell death. Cell. 72:325335. http://dx.doi.org/10.1016/0092-8674(93)90111-3

Hendrix, C.W., C. Flexner, R.T. MacFarland, C. Giandomenico, E.J. Fuchs, E. Redpath, G. Bridger, and G.W. Henson. 2000. Pharmacokinetics and safety of AMD-3100, a novel antagonist of the CXCR-4 chemokine receptor, in human volunteers. Antimicrob. Agents Chemother. 44:16671673. http://dx.doi.org/10.1128/AAC.44.6.1667-1673.2000

Hernandez, P.A., R.J. Gorlin, J.N. Lukens, S. Taniuchi, J. Bohinjec, F. Francois, M.E. Klotman, and G.A. Diaz. 2003. Mutations in the chemokine receptor gene CXCR4 are associated with WHIM syndrome, a combined immunodeficiency disease. Nat. Genet. 34:70-74. http://dx.doi.org/10 $.1038 / \mathrm{ng} 1149$

Honczarenko, M., R.S. Douglas, C. Mathias, B. Lee, M.Z. Ratajczak, and L.E. Silberstein. 1999. SDF-1 responsiveness does not correlate with CXCR4 expression levels of developing human bone marrow B cells. Blood. 94:2990-2998.

Hudson, G., and J.M.Yoffey. 1966. The passage of lymphocytes through the sinusoidal endothelium of guinea-pig bone arrow. Proc. R. Soc. Lond. B Biol. Sci. 165:486-496. http://dx.doi.org/10.1098/rspb.1966.0079

Hwang, I.Y., C. Park, T. Luong, K.A. Harrison, L. Birnbaumer, and J.H. Kehrl. 2013. The loss of Gnai2 and Gnai3 in B cells eliminates B lymphocyte compartments and leads to a hyper-IgM like syndrome. PLoS ONE. 8:e72596. http://dx.doi.org/10.1371/journal.pone.0072596

Iliff, J.J., M. Wang,Y. Liao, B.A. Plogg, W. Peng, G.A. Gundersen, H. Benveniste, G.E.Vates, R. Deane, S.A. Goldman, et al. 2012. A paravascular pathway facilitates CSF flow through the brain parenchyma and the clearance of interstitial solutes, including amyloid $\beta$. Sci. Transl. Med. 4:147ra111. http://dx.doi.org/10.1126/scitranslmed.3003748

Jenne, C.N., A. Enders, R. Rivera, S.R. Watson, A.J. Bankovich, J.P. Pereira,Y. Xu, C.M. Roots, J.N. Beilke, A. Banerjee, et al. 2009. T-bet-dependent S1P5 expression in NK cells promotes egress from lymph nodes and bone marrow. J. Exp. Med. 206:2469-2481. http://dx.doi.org/10.1084/ jem. 20090525

Kerdiles, Y.M., D.R. Beisner, R. Tinoco, A.S. Dejean, D.H. Castrillon, R.A DePinho, and S.M. Hedrick. 2009. Foxo1 links homing and survival of naive T cells by regulating L-selectin, CCR7 and interleukin 7 receptor. Nat. Immunol. 10:176-184. http://dx.doi.org/10.1038/ni.1689

Koni, P.A., S.K. Joshi, U.A. Temann, D. Olson, L. Burkly, and R.A. Flavell. 2001. Conditional vascular cell adhesion molecule 1 deletion in mice: impaired lymphocyte migration to bone marrow. J. Exp. Med. 193:741754. http://dx.doi.org/10.1084/jem.193.6.741

Kuwata, N., H. Igarashi, T. Ohmura, S. Aizawa, and N. Sakaguchi. 1999 Cutting edge: absence of expression of RAG1 in peritoneal B-1 cells detected by knocking into RAG1 locus with green fluorescent protein gene. J. Immunol. 163:6355-6359.

Lämmermann, T., B.L. Bader, S.J. Monkley, T. Worbs, R. Wedlich-Söldner, K. Hirsch, M. Keller, R. Förster, D.R. Critchley, R. Fässler, and M. Sixt. 2008. Rapid leukocyte migration by integrin-independent flowing and squeezing. Nature. 453:51-55. http://dx.doi.org/10.1038/nature06887

Lapidot, T., and O. Kollet. 2002. The essential roles of the chemokine SDF-1 and its receptor CXCR 4 in human stem cell homing and repopulation of transplanted immune-deficient NOD/SCID and NOD/SCID/B2 $\mathrm{m}^{\text {null }}$ mice. Leukemia. 16:1992-2003. http://dx.doi.org/10.1038/sj.leu.2402684

Leuker, C.E., M. Labow, W. Müller, and N. Wagner. 2001. Neonatally induced inactivation of the vascular cell adhesion molecule 1 gene impairs B cell localization and $\mathrm{T}$ cell-dependent humoral immune response. J. Exp. Med. 193:755-768. http://dx.doi.org/10.1084/jem.193.6.755

Li, Y., H. Li, D. Ni, and M. Weigert. 2002. Anti-DNA B cells in MRL/lpr mice show altered differentiation and editing pattern. J. Exp. Med. 196:1543-1552. http://dx.doi.org/10.1084/jem.20021560

Lichtman, M.A., and P. Santillo. 1986. Red cell egress from the marrow? visà-tergo. Blood Cells. 12:11-23.

Liles, W.C., H.E. Broxmeyer, E. Rodger, B. Wood, K. Hübel, S. Cooper, G. Hangoc, G.J. Bridger, G.W. Henson, G. Calandra, and D.C. Dale. 2003. Mobilization of hematopoietic progenitor cells in healthy volunteers by AMD3100, a CXCR4 antagonist. Blood. 102:2728-2730. http://dx.doi .org/10.1182/blood-2003-02-0663

Ma, Q., D. Jones, and T.A. Springer. 1999. The chemokine receptor CXCR4 is required for the retention of $\mathrm{B}$ lineage and granulocytic precursors within the bone marrow microenvironment. Immunity. 10:463-471. http://dx.doi.org/10.1016/S1074-7613(00)80046-1

Madisen, L., T.A. Zwingman, S.M. Sunkin, S.W. Oh, H.A. Zariwala, H. Gu, L.L. Ng, R.D. Palmiter, M.J. Hawrylycz, A.R. Jones, et al. 2010. A robust and high-throughput Cre reporting and characterization system for the whole mouse brain. Nat. Neurosci. 13:133-140. http://dx.doi.org/ $10.1038 / \mathrm{nn} .2467$

Mazo, I.B., J.C. Gutierrez-Ramos, P.S. Frenette, R.O. Hynes, D.D. Wagner, and U.H. von Andrian. 1998. Hematopoietic progenitor cell rolling in bone marrow microvessels: parallel contributions by endothelial selectins and vascular cell adhesion molecule 1.J. Exp. Med. 188:465-474. http:// dx.doi.org/10.1084/jem.188.3.465

Nie, Y., J. Waite, F. Brewer, M.J. Sunshine, D.R. Littman, and Y.R. Zou. 2004 The role of CXCR4 in maintaining peripheral B cell compartments and humoral immunity. J. Exp. Med. 200:1145-1156. http://dx.doi.org/ $10.1084 / \mathrm{jem} .20041185$

Papayannopoulou, T., G.V. Priestley, H. Bonig, and B. Nakamoto. 2003. The role of G-protein signaling in hematopoietic stem/progenitor cell mobilization. Blood. 101:4739-4747. http://dx.doi.org/10.1182/blood-2002$09-2741$

Pelanda, R., E. Hobeika, T. Kurokawa, Y. Zhang, S. Kuppig, and M. Reth. 2002. Cre recombinase-controlled expression of the mb-1 allele. Genesis. 32:154-157. http://dx.doi.org/10.1002/gene.10070

Pereira, J.P., J. An, Y. Xu, Y. Huang, and J.G. Cyster. 2009. Cannabinoid receptor 2 mediates the retention of immature B cells in bone marrow sinusoids. Nat. Immunol. 10:403-411. http://dx.doi.org/10.1038/ni.1710

Pereira, J.P., Y. Xu, and J.G. Cyster. 2010. A role for S1P and S1P1 in immature-B cell egress from mouse bone marrow. PLoS ONE. 5:e9277. http://dx.doi.org/10.1371/journal.pone.0009277

Regard, J.B., H. Kataoka, D.A. Cano, E. Camerer, L. Yin, Y.W. Zheng, T.S Scanlan, M. Hebrok, and S.R. Coughlin. 2007. Probing cell type-specific functions of Gi in vivo identifies GPCR regulators of insulin secretion. J. Clin. Invest. 117:4034-4043.

Schlenner, S.M., V. Madan, K. Busch, A. Tietz, C. Läufle, C. Costa, C. Blum, H.J. Fehling, and H.R. Rodewald. 2010. Fate mapping reveals separate origins of T cells and myeloid lineages in the thymus. Immunity. 32:426436. http://dx.doi.org/10.1016/j.immuni.2010.03.005

Serbina, N.V., and E.G. Pamer. 2006. Monocyte emigration from bone marrow during bacterial infection requires signals mediated by chemokine 
receptor CCR2. Nat. Immunol. 7:311-317. http://dx.doi.org/10.1038/ ni1309

Shi, C., T. Jia, S. Mendez-Ferrer, T.M. Hohl, N.V. Serbina, L. Lipuma, I. Leiner, M.O. Li, P.S. Frenette, and E.G. Pamer. 2011. Bone marrow mesenchymal stem and progenitor cells induce monocyte emigration in response to circulating toll-like receptor ligands. Immunity. 34:590-601. http:// dx.doi.org/10.1016/j.immuni.2011.02.016

Sugita, K., K. Kabashima, J. Sakabe, R. Yoshiki, H. Tanizaki, and Y. Tokura. 2010. FTY720 regulates bone marrow egress of eosinophils and modulates late-phase skin reaction in mice. Am. J. Pathol. 177:1881-1887. http://dx.doi.org/10.2353/ajpath.2010.100119

Sugiyama, T., H. Kohara, M. Noda, and T. Nagasawa. 2006. Maintenance of the hematopoietic stem cell pool by CXCL12-CXCR4 chemokine signaling in bone marrow stromal cell niches. Immunity. 25:977-988. http://dx.doi.org/10.1016/j.immuni.2006.10.016

Tamamura, H., A. Omagari, K. Hiramatsu, K. Gotoh, T. Kanamoto, Y. Xu, E. Kodama, M. Matsuoka, T. Hattori, N. Yamamoto, et al. 2001. Development of specific CXCR4 inhibitors possessing high selectivity indexes as well as complete stability in serum based on an anti-HIV peptide T140. Bioorg. Med. Chem. Lett. 11:1897-1902. http://dx.doi.org/10.1016/ S0960-894X(01)00323-7

Tavassoli, M., and J.M.Yoffey. 1983. Bone Marrow: Structure and Function. A.R. Liss, New York. 300 pp.

Ueda, Y., K. Yang, S.J. Foster, M. Kondo, and G. Kelsoe. 2004. Inflammation controls B lymphopoiesis by regulating chemokine CXCL12 expression. J. Exp. Med. 199:47-58. http://dx.doi.org/10.1084/jem.20031104
Walzer, T., L. Chiossone, J. Chaix, A. Calver, C. Carozzo, L. Garrigue-Antar, Y. Jacques, M. Baratin, E. Tomasello, and E.Vivier. 2007. Natural killer cell trafficking in vivo requires a dedicated sphingosine 1-phosphate receptor. Nat. Immunol. 8:1337-1344. http://dx.doi.org/10.1038/ ni1523

Wang, A., A.M. Fairhurst, K. Tus, S. Subramanian, Y. Liu, F. Lin, P. Igarashi, X.J. Zhou, F. Batteux, D. Wong, et al. 2009a. CXCR4/CXCL12 hyperexpression plays a pivotal role in the pathogenesis of lupus. J. Immunol. 182:4448-4458. http://dx.doi.org/10.4049/jimmunol.0801920

Wang, Y., L. Cui, W. Gonsiorek, S.H. Min, G. Anilkumar, S. Rosenblum, J. Kozlowski, D. Lundell, J.S. Fine, and E.P. Grant. 2009b. CCR2 and CXCR 4 regulate peripheral blood monocyte pharmacodynamics and link to efficacy in experimental autoimmune encephalomyelitis. J. Inflamm. (Lond.) 6:32. http://dx.doi.org/10.1186/1476-9255-6-32

Wardemann, H., S. Yurasov, A. Schaefer, J.W. Young, E. Meffre, and M.C. Nussenzweig. 2003. Predominant autoantibody production by early human B cell precursors. Science. 301:1374-1377. http://dx.doi.org/10 $.1126 /$ science. 1086907

Woolf, E., I. Grigorova, A. Sagiv, V. Grabovsky, S.W. Feigelson, Z. Shulman, T. Hartmann, M. Sixt, J.G. Cyster, and R. Alon. 2007. Lymph node chemokines promote sustained $\mathrm{T}$ lymphocyte motility without triggering stable integrin adhesiveness in the absence of shear forces. Nat. Immunol. 8:1076-1085. http://dx.doi.org/10.1038/ni1499

Zachariah, M.A., and J.G. Cyster. 2010. Neural crest-derived pericytes promote egress of mature thymocytes at the corticomedullary junction. Science. 328:1129-1135. http://dx.doi.org/10.1126/science.1188222 